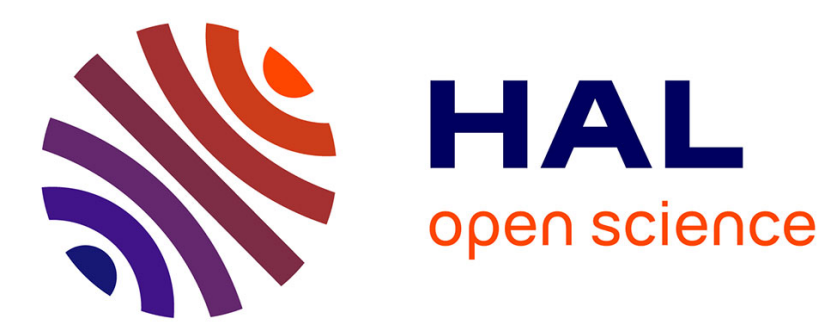

\title{
Amazonian Northern Mid-Latitude Glaciation on Mars: A Proposed Climate Scenario
}

Jean-Baptiste Madeleine, François Forget, James W. Head, Benjamin

Levrard, Franck Montmessin, Ehouarn Millour

\section{- To cite this version:}

Jean-Baptiste Madeleine, François Forget, James W. Head, Benjamin Levrard, Franck Montmessin, et al.. Amazonian Northern Mid-Latitude Glaciation on Mars: A Proposed Climate Scenario. Icarus, 2009, 203 (2), pp.390-405. 10.1016/j.icarus.2009.04.037 . hal-00399202

\section{HAL Id: hal-00399202 https://hal.science/hal-00399202}

Submitted on 11 Apr 2016

HAL is a multi-disciplinary open access archive for the deposit and dissemination of scientific research documents, whether they are published or not. The documents may come from teaching and research institutions in France or abroad, or from public or private research centers.
L'archive ouverte pluridisciplinaire HAL, est destinée au dépôt et à la diffusion de documents scientifiques de niveau recherche, publiés ou non, émanant des établissements d'enseignement et de recherche français ou étrangers, des laboratoires publics ou privés. 
15 Tables: 1

16 Figures: 13

\title{
Glaciation on Mars:
}

\section{A Proposed Climate Scenario}

\author{
J.-B. Madeleine ${ }^{\mathrm{a}}$, F. Forget ${ }^{\mathrm{a}}$, James W. Head ${ }^{\mathrm{b}}$, B. Levrard ${ }^{\mathrm{c}}$, \\ F. Montmessin ${ }^{\mathrm{d}}$, and E. Millour ${ }^{\mathrm{a}}$
}

${ }^{a}$ Laboratoire de Météorologie Dynamique, CNRS/UPMC/IPSL, 4 place Jussieu, BP99, 75252, Paris Cedex 05, France

${ }^{\mathrm{b}}$ Department of Geological Sciences, Brown University, Providence, RI 02912, $U S A$

${ }^{\mathrm{c}}$ Astronomie et Systèmes Dynamiques, IMCCE-CNRS UMR 8028, 77 Avenue Denfert-Rochereau, 75014 Paris, France

${ }^{\mathrm{d}}$ Service d'Aéronomie, CNRS/UVSQ/IPSL, Réduit de Verrières, Route des Gatines, 91371 Verrières-le-Buisson Cedex, France

Email address: jbmlmd@lmd.jussieu.fr (J.-B. Madeleine).

Article published in Icarus 0 (2016) 1-54 
17 Proposed Running Head:

18 A Climate Scenario for Northern Mid-Latitude Glaciation

19 Please send Editorial Correspondence to:

20

21 Jean-Baptiste Madeleine

22 Laboratoire de Météorologie Dynamique, UMR 8539

23 Institut Pierre Simon Laplace

24 Université Paris 6, BP 99

254 place Jussieu

2675252 Paris cedex 05, FRANCE

${ }_{27}$ Email: jbmlmd@lmd.jussieu.fr

28 Phone: +33144278456

$29 \quad$ Fax: +33144276272 
Recent geological observations in the northern mid-latitudes of Mars show evidence for past glacial activity during the late Amazonian, similar to the integrated glacial landsystems in the Dry Valleys of Antarctica. The large accumulation of ice (many hundreds of meters) required to create the observed glacial deposits points to significant atmospheric precipitation, snow and ice accumulation, and glacial flow. In order to understand the climate scenario required for these conditions, we used the LMD (Laboratoire de Météorologie Dynamique) Mars GCM (General Circulation Model), which is able to reproduce the present-day water cycle, and to predict past deposition of ice consistent with geological observations in many cases. Prior to this analysis, however, significant mid-latitude glaciation had not been simulated by the model, run under a range of parameters.

In this analysis, we studied the response of the GCM to a wider range of orbital configurations and water ice reservoirs, and show that during periods of moderate obliquity $\left(\epsilon=25-35^{\circ}\right)$ and high dust opacity $\left(\tau_{\text {dust }}=1.5-2.5\right)$, broadscale glaciation in the northern mid-latitudes occurs if water ice deposited on the flanks of the Tharsis volcanoes at higher obliquity is available for sublimation. We find that high dust contents of the atmosphere increase its water vapor holding capacity, thereby moving the saturation region to the northern mid-latitudes. Precipitation events are then controlled by topographic forcing of stationary planetary waves and transient weather systems, producing surface ice distribution and amounts that are consistent with the geological

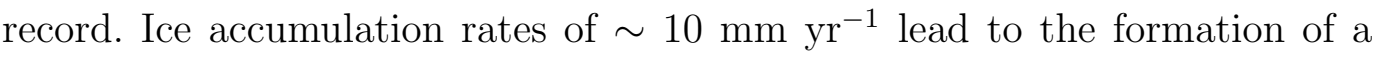
500-1000 m thick regional ice sheet that will produce glacial flow patterns consistent with the geological observations. 
56 Keywords: MARS, ATMOSPHERE, DYNAMICS, CLIMATE, GEOLOGI57 CAL PROCESSES 
1 Introduction: Evidence for northern mid-latitude ice presence and glaciation on Mars

Evidence for the influence of non-polar ice deposition on geomorphic features and processes became available as a result of the comprehensive global coverage provided by the Viking Orbiter imaging system. For example, Squyres $(1978,1979)$ attributed a variety of landforms (e.g., lobate debris aprons, lineated valley fill, concentric crater fill, terrain softening) to the creep of the martian regolith aided by the deformation of ground ice at latitudes higher than $\sim 30^{\circ}$. Other workers (e.g., Lucchitta (1981)) noted that many of these features appeared to represent not just ice-assisted creep, but rather more substantial glacial-like flow. More recently, new high-resolution data have shown the presence of deposits interpreted to represent the remnants of extensive glacial landsystems that formed in the parts of the northern mid-latitudes during the Amazonian (e.g., Head et al. (2006b,a); Head and Marchant (2006); Dickson et al. (2008)). These recent analyses show the widespread development of valley glaciers, piedmont glaciers, plateau glaciation, and the development of extensive glacial landsystems across the northern mid-latitudes (see Fig. 1). Detailed examination of these deposits shows that ice may have reached thicknesses of up to $2-2.5 \mathrm{~km}$ in some regions along the dichotomy boundary (e.g., Head et al. (2006b,a); Dickson et al. (2008)). Clearly, the current atmosphere and climate do not permit the accumulation of snow and ice at the level necessary to produce such deposits. This raises the question: Under what past climate conditions could the accumulation of snow and ice occur to produce the types of glacial deposits seen in the northern mid-latitudes?

[Fig. 1 about here.] 
Despite several climate modeling studies (Haberle et al., 2000; Mischna et al., 2003; Levrard et al., 2007; Forget et al., 2006; Montmessin et al., 2007), the origin of the northern mid-latitude glaciation has remained an enigma. Here, we extend this previous work to a wider range of climate parameters, and show that this broad-scale glaciation occurs if we assume that atmospheric dust content is higher than today (Newman et al., 2005), and that water ice deposited on the flanks of the Tharsis volcanoes is available for sublimation (Forget et al., 2006). Using the LMD (Laboratoire de Météorologie Dynamique) Martian Global Climate Model (Forget et al., 1999), we thus address the following questions:

(1) What climatic mechanism can explain the formation of water-ice deposits of hundreds of meters thickness in the northern mid-latitudes of Mars?

(2) What accounts for the regionally heterogeneous longitudinal distribution of the deposits in the $30-50^{\circ} \mathrm{N}$ band?

(3) How are these glaciations related to orbital variations and can we determine the probable geologic periods of activity?

(4) What are the impacts of these deposits on the recent history of the martian water cycle?

(5) Is there any evidence for ice sequestration (removal of water ice from the system) during these glacial phases?

After a short review of the recent climatic history and description of our methods, we analyze in the following sections the climate of the northern mid-latitude glaciation. Then, we study its sensitivity to climate parameters, and finally discuss an updated climatic scenario for late Amazonian ice ages. 


\section{Geological evidence for orbital-driven climate change on Mars}

\subsection{Geomorphological settings}

Accumulations of snow and ice, and glacial and periglacial landforms on Mars exhibit a range of morphologies typical of different types of deposits, glaciers and glacial subenvironments. Many of these show a stratigraphy which has been interpreted to record climate shifts due to orbital variations. In addition to the mid-latitude glacier deposits described in section 1, numerous other examples of ice accumulation and glacial morphologies have been reported (Head and Marchant, 2008), the major ones being 1) the North and South Polar Layered Deposits, 2) the Latitude Dependent Mantle and 3) the Tropical Mountain Glaciers.

- Polar layered deposits consist of alternating dark and bright layers of ice mixed in different proportion with dust. They are visible on the walls of the north polar cap, and form a thick stratigraphic sequence seen in outcrop (Milkovich and Head, 2005) and in the subsurface with the SHARAD radar instrument on board Mars Reconnaissance Orbiter (Phillips and 26 colleagues, 2008). Recent detailed analysis by the High-Resolution Imaging Science Experiment (HiRISE) on board MRO revealed layers whose true thickness is as low as $10 \mathrm{~cm}$, and whose apparent brightness is not only the result of layer composition, but also of surfacial frost and roughness (Herkenhoff et al., 2007), explaining why the interpretation of the polar layered deposit frequency signals is so difficult (Laskar et al., 2002; Milkovich and Head, 2005; Levrard et al., 2007). 
- The north and south latitude dependent mantles are meters thick layered deposits draped on both hemispheres above $50^{\circ}$, and present in partially degraded states from $30^{\circ}$ to $50^{\circ}$ latitude. They are revealed in MOLA data by a latitudinal trend of roughness and concavity at $0.6 \mathrm{~km}$ baseline (Kreslavsky and Head, 2000, 2002), and in MOC images by various latitude-dependent geomorphologies (Mustard et al., 2001; Milliken et al., 2003). These results led to the conclusion that the latitude dependent mantle was an ice and dust cover of atmospheric origin, deposited during recent ice ages and currently undergoing desiccation at lower latitudes (Head et al., 2003).

- Tropical mountain glaciers refer to large mountain glacial systems on the western flanks of the Tharsis Montes and Olympus Mons (Head and Marchant, 2003). The largest of these, at Arsia Mons, covers an area of $\sim 170.000 \mathrm{~km}^{2}$. Exploration of cold-based glaciers in the Antarctic Dry Valleys, one of the most Mars-like environments on Earth, has led to an understanding of the cold-based nature of most Mars glaciers and the interpretation of cold-based glacial deposits such as drop moraines, sublimation tills and debris-covered glaciers (Marchant and Head, 2007). The identification of deposits interpreted to result from cold-based glaciation in high-resolution images has permitted the reconstruction of these tropical mountain glaciers (Head and Marchant, 2003; Shean et al., 2005, 2007; Milkovich et al., 2006; Kadish et al., 2008), identification of the climatic conditions necessary for their formation (e.g., Forget et al. (2006)), and the formulation of glacial flow models consistent with the geological features and settings (e.g., Fastook et al. (2008)). Multiple arcuate ridges have been interpreted as drop moraines, lobate deposits represent debris-covered glaciers, and knobby terrain is interpreted to represent sublimation tills formed as the glaciers collapsed. These deposits show 
numerous episodes of advance and retreat during the late Amazonian.

Ages obtained through crater size-frequency analyses span the period from less than 10 Myr for the latitude dependent mantle (Head et al., 2003) to 10200 Myr for the tropical mountain glaciers (Shean et al., 2005). These data, together with the distribution of several other latitudinally distributed icerelated deposits (e.g., Head and Marchant (2008)) suggest long-term glacial activity during the Amazonian.

\subsection{Mars orbital variations}

Climate changes on Mars are driven by insolation variations comparable to terrestrial Milankovitch cycles. Spin-axis and orbital parameter variations of Mars are much larger than on Earth, and their evolution can only be calculated over a few millions of years (Laskar and Robutel, 1993) due to the strongly chaotic nature of the solutions prior to this time. A robust solution for the last 10 Myr, however, has been derived by Laskar et al. (2004), and is currently used as a guideline to explore recent climate changes. Variations of obliquity and eccentricity are given on Fig. 2. Insolation varies with a short $51 \mathrm{kyr}$ period due to climatic precession, a 120 kyr period in obliquity, two 95 and 99 kyr periods in eccentricity, with the whole signal being finally modulated with a 2.4 Myr period (Laskar et al., 2002). 


\subsection{Paleoclimate simulations}

These geomorphological and orbital analyses suggest that under past orbital configurations, atmospheric mechanisms were available and operating to deposit significant amounts of ice in widespread regions of Mars, from the latitude dependent mantle covering at least $23 \%$ of the planet (Kreslavsky and Head, 2002) to the regional mid-latitude valley and tropical mountain glaciers.

Concurrently, developments in climate modeling are providing robust tools to explore this past water cycle (Haberle et al., 2000; Mischna et al., 2003; Levrard et al., 2007; Forget et al., 2006; Montmessin et al., 2007). For example, using the orbital calculations of Laskar et al. (2004) and the LMD/GCM (Forget et al., 1999), Levrard et al. (2004) came to the conclusion that the tropical mountain glaciers and the latitude dependent mantle can be formed during periods of high $\left(35-40^{\circ}\right)$ and low $\left(15-25^{\circ}\right)$ mean obliquity respectively by atmospheric water exchange between tropical and polar reservoirs. Indeed, the north polar cap becomes unstable for obliquities higher than $\sim 35^{\circ}$, resulting in a total water column of $\sim 3000 \mathrm{pr} . \mu \mathrm{m}$ during the northern summer, compared to a present-day observed value of $\sim 60$ pr. $\mu \mathrm{m}$ (Fouchet and 10 colleagues, 2007). Under low dust opacity conditions and $45^{\circ}$ obliquity, precipitation and deposition of ice on the western flanks of Tharsis Montes and Olympus Mons by adiabatic cooling of strong westerly winds is then possible (Forget et al.,

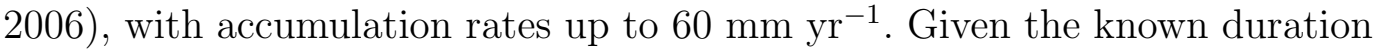
of high obliquity excursions, such an accumulation rate can create $\sim 3 \mathrm{~km}$ thick glaciers on the volcanoes consistent with geological observations (e.g., Shean et al. (2005); Fastook et al. (2008)). Under the same orbital conditions and by switching the water ice source from the north pole to the south pole, 
a significant accumulation of ice is also predicted in eastern Hellas (Forget et al., 2006) where evidence for glacial flow has been identified (Crown et al., 1992; Head et al., 2005). When returning to lower obliquities and assuming that tropical mountain glaciers are new sources of atmospheric water vapor, Levrard et al. (2004) showed that an accumulation of ice of several millimeters per year occurs above $60^{\circ}$ in both hemispheres, providing a possible origin for the latitude dependent mantle. In the same study, complete desiccation of the tropical mountain glaciers finally leads to a decreasing amount of atmospheric water vapor and retreat of the latitude dependent mantle to the poles, to form the polar layered deposits. Montmessin et al. (2007) went one step further by exploring the effect of a reversed perihelion $25 \mathrm{kyr}$ ago, and found a possible origin for the south residual water ice cap (Titus et al., 2003; Bibring et al., 2004).

\section{Numerical simulations under new paleoclimatic conditions}

\subsection{Method of analysis}

Insolation variations result from changes in the obliquity $\epsilon$, the eccentricity $e$, and the areocentric longitude of the Sun at perihelion $\mathrm{L}_{\mathrm{p}}$ (see for instance Fig. 1 of Armstrong et al. (2004)). These three parameters are able to produce major changes in insolation, atmospheric circulation, and thus in dust lifting rates and distribution of surface water-ice. Consequently, to define a climatic scenario, we first need to assign a given orbital configuration $\left(\epsilon, e, \mathrm{~L}_{\mathrm{p}}\right)$. Because the dust cycle is not predicted by the climate model, we also need to assign a dust content of the atmosphere under these past orbital conditions, 
given by the dust optical depth $\tau_{d u s t}$ at $0.67 \mu \mathrm{m}$ (Pollack et al., 1979). $\tau_{\text {dust }}$ is typically equal to $0.2-0.4$ under common conditions, but can reach values of 1-2.5 during local dust storms, and 5 during global dust storms. Finally, the location of surface water-ice reservoirs (WIR) must be specified to generate a water cycle. These locations are given by the acronyms N/SPC (North/South polar cap), LDM (latitude-dependent mantle) and TMG (tropical mountain glaciers). A climatic scenario is then a point in the parameter space defined by $\underline{x}=\left\{\epsilon, e, \mathrm{~L}_{\mathrm{p}}, \tau_{\text {dust }}, \mathrm{WIR}\right\}$. We ran a set of $5.625 \times 3.75$-degree resolution simulations limited to the lower atmosphere (from the ground to $\simeq 50 \mathrm{~km}$ ) in the parameter space defined by $\epsilon=\left(15,25,35,45^{\circ}\right), e=(0,0.1), \mathrm{L}_{\mathrm{p}}=\left(90,270^{\circ}\right)$, $\tau_{\text {dust }}=(0.2,1,2.5)$, and WIR $=(\mathrm{NPC}, \mathrm{SPC}, \mathrm{TMG})$.

Given the large number of combinations, studying the specific climatic origin of the mid-latitude glaciation presents an imposing task. However, it is possible to approach solutions by systematically comparing the predicted water cycle to geological observations. Among the two dozen simulations performed with this approach, the best conditions for development of the mid-latitude glaciation was obtained at point $x_{r e f}=\left(35^{\circ}, 0.1,270^{\circ}, 2.5, \mathrm{TMG}\right)$. Coordinates of the other simulations of interest will further be noted as $x_{i}$, and analyzed in the sensitivity study of section 5.2. $x_{0}$ refers to present-day conditions (i.e. $\left.\epsilon=25.19^{\circ}, e=0.093, \mathrm{~L}_{\mathrm{p}}=251^{\circ}\right)$ with a time-varying dust opacity that follows the observations of Mars Global Surveyor Thermal Emission Spectrometer acquired during the martian year 24 (1999-2000, Smith (2004)), and a water-ice reservoir corresponding to the north polar cap. All the results will be shown for the sixth year of simulation, once an equilibrium is reached. 
The terrestrial GCM of the Laboratoire de Météorologie Dynamique (LMD, Paris) has been adapted to Mars in 1989 by changing the radiative transfer and adding the $\mathrm{CO}_{2}$ cycle (Forget et al., 1998). It was the first model to reproduce a self-working Mars, and pressure variations consistent with the Viking Landers observations of transient weather systems (Hourdin et al., 1993). Since then, two teams from the LMD and the department of Atmospheric, Oceanic and Planetary Physics (AOPP), Oxford, have been developing two grid-point and spectral models in parallel, with a full description of the planetary boundary layer, the propagation of gravity waves, the dust cycle (Newman et al., 2002), the water cycle (Montmessin et al., 2004), the role of the regolith (Böttger et al., 2005), the thermosphere (Angelats i Coll et al., 2005), the ozone photochemistry (Lefèvre et al., 2004), and the HDO cycle (Montmessin et al., 2005). A detailed description of the model can be found in Forget et al. (1999), and we only review here the relevant processes of the Mars water cycle, such as the dust and water radiative effects, the formation of water-ice clouds, and the stability of surface ice deposits.

\subsubsection{Dust radiative effects:}

From the observed or assigned values of $\tau_{d u s t}$, a dust mixing ratio is deduced at a reference pressure level of $p_{0}=700 \mathrm{~Pa}$, the vertical profile being then set to constant under this pressure level, and decreasing above (Forget et al., 1999). Visible and near-infrared radiative effects of dust are taken into account by calculating the radiative transfer in two different bands : 0.1-0.5 $\mu \mathrm{m}$ and 0.5-5 $\mu \mathrm{m}$. Thermal IR absorption and emission of dust is also computed in the 
silicate band $(5-11.5 \mu \mathrm{m})$ and the rest of the IR band $(20-200 \mu \mathrm{m})$. The ratio between the visible and the $9 \mu \mathrm{m}$ dust opacity $\left(\tau_{0.67 \mu m} / \tau_{9 \mu m}\right)$ is essential to predict the energy distribution between the atmosphere and the surface, and a value of 2 is assigned in the GCM, following a method described in Forget (1998)

\subsubsection{Water radiative effects:}

At the moment, water vapor and cloud radiative effects are neglected in the GCM. Water vapor column can be increased by an order of magnitude under past conditions (Mischna et al., 2003; Forget et al., 2006), and broad scale cloud cover can reach significant optical thickness. Clouds change the lower atmosphere temperature by both reflecting more sunlight in the shortwave domain, and increasing the thermal infrared opacity at cloud altitude (Wilson et al., 2007). Resulting temperature change feeds back on nucleation rates, water vapor amount and dust scavenging by ice particles (Rodin et al., 1999). Development of a new model, accounting for these complex processes, is underway.

\subsubsection{Water transport and cloud formation:}

Water vapour and ice crystals are taken into account in the model by adding two (radiatively passive) tracers that are advected conservatively by the Global Climate Model. A Van Leer scheme I (van Leer, 1977; Hourdin and Armengaud, 1999) accounts for the global transport of these tracers, whereas subgrid processes, i.e. turbulent mixing and convective adjustment, are parameterized with a diffusion equation and an energy conserving scheme, respectively (Hour- 
din et al., 1993; Forget et al., 1999). The crystal size is predicted by the cloud microphysics described in Montmessin et al. (2002). When a parcel of the atmosphere is supersaturated, the increasing mass of water-ice is predicted by taking into account the number of nuclei, which is a function of the dust content of the atmosphere. Consequently the model accounts for ice-crystal microphysics and interaction with dust nuclei. The model also accounts for sedimentation of ice crystals (Montmessin et al., 2004), but scavenging of atmospheric dust and subsequent feedbacks are not yet taken into account.

\subsubsection{Stability of surface ice deposits:}

Soil and surface temperatures depend on the balance between incoming fluxes and thermal conduction in the soil (Hourdin et al., 1993). The conduction equation is calculated by using the thermal inertia deduced from IRTM and TES observations. Sublimation of surface ice deposits is controlled by the surface turbulent flux:

$$
F_{w}=\rho_{1} C_{d} U_{1}\left(q_{s a t}-q_{w v}\right),
$$

where $\rho_{1}$ is the atmospheric density in the first layer of the GCM (up to $5 \mathrm{~m}$ high), $U_{1}$ the wind speed in the same layer, and $C_{d}$ the drag coefficient (Forget et al., 1999; Montmessin et al., 2004). $q_{\text {sat }}$ is the saturation mass mixing ratio of water vapor at the ground temperature, and $q_{w v}$ is the actual mass mixing ratio of water vapor in the first layer. In other words, the surface ice sublimates if the first layer of the model is not saturated, i.e. $q_{s a t}>q_{w v}$. On the contrary, ice can build up if $q_{s a t}<q_{w v}$, or if the atmosphere itself is supersaturated, in which case precipitation leads to deposition of ice crystals onto the surface. It is worth noting that $q_{s a t} \propto p_{\text {sat }} / p_{s}$, where $p_{\text {sat }}$ is the saturation pressure and $p_{s}$ 
the actual surface pressure. Given the fact that saturation pressure exponentially increases with temperature (Clausius-Clapeyron equation), sublimation is dependent, to first order, on summer temperatures.

The positive ice-albedo feedback is also taken into account by setting the surface albedo to 0.4 when deposits are more than $5 \mu \mathrm{m}$ thick. Thermal inertia feedback is not activated until section 5.3, where its impact on surface water ice stability is analyzed. Finally, water vapor is not allowed to diffuse into the regolith.

\section{Results: From present-day climate to the northern mid-latitude glaciation}

To explore the meteorological conditions under which a regional ice sheet may have accumulated and grown in the northern mid-latitudes, we describe in the subsequent sections the manner in which the Martian climate system can evolve from its present-day interglacial state to an ice age by gradually changing the orbital parameters, the water-ice sources and the dust content of the atmosphere. Our analysis will be based on Fig. 3, 4 and 5, that respectively show the annual evolution of the water cycle, the zonal structure of the northern winter atmosphere, and the relationship between stationary planetary waves and cloud distribution at this season, each for three different simulations. The first one corresponds to present-day climate, while the second and third ones correspond to $35^{\circ}$ obliquity and equatorial water source under clear $\left(\tau_{\text {dust }}=0.2\right)$ and dusty $\left(\tau_{\text {dust }}=2.5\right)$ conditions, respectively. We will particularly focus on the onset of the mid-latitude precipitation activity during late northern fall $\left(\mathrm{L}_{\mathrm{S}}=240-270^{\circ}\right)$. 
362 and $\mathrm{L}_{\mathrm{S}}=120^{\circ}$.

[Fig. 3 about here.]

Following the mapping of water vapor by the Viking Mars Atmospheric Water Detector (MAWD) in the late 1970s (Jakosky and Farmer, 1982), infrared spectrometer data from the Mars Global Surveyor, Mars Express and Mars Reconnaissance Orbiter missions are providing a detailed picture of the Mars water cycle from global to regional scale. Annual zonal-mean evolution of the water cycle, as simulated by the LMD/GCM, is illustrated in Fig. 3.a, with contours corresponding to the precipitable water vapor column in micrometers (pr. $\mu \mathrm{m})$, and shaded regions to water-ice clouds (same unit). The main source of the water cycle comes from the release of up to $60 \mathrm{pr} . \mu \mathrm{m}$ of water vapor during late northern spring and summer, as observed by Smith (2002); Fouchet and 10 colleagues (2007). Visible and near-infrared imaging of the northern polar regions (see Fig. 11 of Wang and Ingersoll (2002); Bibring and 10 colleagues (2005); Langevin et al. (2005)) during this period revealed the recession of a seasonal $\mathrm{CO}_{2}$ frost (James and Cantor, 2001; Kieffer and Titus, 2001) followed by a fine-grained $\mathrm{H}_{2} \mathrm{O}$ ice edge, whose sublimation finally exposes the perennial $\mathrm{H}_{2} \mathrm{O}$ cap to summer insolation. All this results in the slow 1 increase of the water vapor column observed in Fig. 3.a, between $\mathrm{L}_{\mathrm{S}}=50^{\circ}$

363 4.1.1 Aphelion cloud belt and the "Clancy" effect:

364 Then water vapor reaches the subsolar point, where advection into the over365 turning Hadley cell occurs (see the descending 25 pr. $\mu \mathrm{m}$ isocontour in Fig. 3.a, 
and previous work by Houben et al. (1997); Richardson and Wilson (2002)).

Adiabatic expansion and cooling of the rising parcels increases their relative humidity, until condensation and formation of the Aphelion cloud belt occurs (Kahn, 1984; Clancy et al., 1996; Wolff et al., 1999; Wang and Ingersoll, 2002). These clouds appear during mid-spring and summer around the northern tropics, as predicted in Fig. 3.a (see the water-ice rich shaded region in the $\pm 30^{\circ}$ latitude band around $\mathrm{L}_{\mathrm{S}}=90^{\circ}$ ). Sublimation of the Aphelion cloud belt around $\mathrm{L}_{\mathrm{S}}=150^{\circ}$ is mainly due to a warming of the atmosphere as we leave the Aphelion season (Richardson et al., 2002), during which the condensation level (known as the hygropause) was low, and thus favorable to cloud formation. The existence of low hygropause conditions in the rising branch of the Hadley cell tends to retain water vapor in the summer hemisphere, a key phenomenon first described in Clancy et al. (1996), and since called "the Clancy effect". Its paleoclimatic implications when aphelion occurred during southern summer 25 kyr ago have been studied by Montmessin et al. (2007), who used the LMD/GCM to explain the possible origin of the south residual cap (see section 2). We will see that the Clancy effect is also key to understanding the northern mid-latitude glaciation.

\subsubsection{Onset of the northern winter season:}

As summer comes to the southern uplands and cold polar night arrives in the northern high latitudes, $\mathrm{CO}_{2}$ and $\mathrm{H}_{2} \mathrm{O}$ ice start to sublime in the south 87 polar regions, while the northern atmosphere approaches saturation, to form s the polar hood.

Considering the departures from zonally symmetric flow is essential to capture 
the behaviour of the south seasonal cap and north polar hood. It is here instructive to further describe this present-day northern winter climate, before analyzing the changes that occurred during glacial excursions.

[Fig. 4 about here.]

Figure 4.a illustrates the zonal mean circulation predicted by the LMD/GCM for the $\mathrm{L}_{\mathrm{S}}=240-270^{\circ}$ period. It is characterized by 1) an intense meridional temperature gradient that results in, and from, a westerly (west $\rightarrow$ east) jet in the winter hemisphere and an easterly jet in the southern tropics, 2) a cross-equatorial Hadley circulation that adiabatically heats the atmosphere in its descending branch, explaining the comma-shaped temperature inversion in the northern mid-latitudes (Haberle et al., 1993; Forget et al., 1999), and 3) a surface westerly jet around $30^{\circ} \mathrm{S}$, resulting from eastward acceleration of the flow in the return branch of the Hadley cell through momentum conservation (Joshi et al., 1997). The zonal-mean water vapor distribution during the same period is illustrated in Fig. 4.b along with the ice mixing ratio in Fig. 4.c. Two regions of enhanced water vapor can be distinguished, around $60^{\circ} \mathrm{S}$ and $30^{\circ} \mathrm{N}$, that correspond respectively to the sublimation of the southern seasonal cap and northward transport by the upper-branch of the Hadley cell. These general dynamics are clearly highlighted by the $300 \cdot 10^{-6} \mathrm{~kg} \mathrm{~kg}^{-1}$ line in Fig. 4.b. An equatorial cloud belt appears in Fig. 4.c at much higher altitudes than the Aphelion one, and thus allows water vapor to be advected in the northern hemisphere, and to finally reach the winter polar vortex.

This water vapor condenses at the edge of the polar night, where poleward advection of water vapor by the mid-latitude non-axisymmetric circulation plays a major role in the formation of the polar hood (see the enhanced ice 
mixing ratio around $50^{\circ} \mathrm{N}$ in Fig. 4.c). These departures from zonal-mean circulation are due to traveling and stationary waves. These waves result in poleward or equatorward advection of tracers and horizontal mixing.

[Fig. 5 about here.]

A more detailed understanding of the polar hood structure can thus be gained through the analysis of the stationary vortex asymmetries and the resulting cloud pattern. Figure 5.a is a polar stereographic map of the mean zonal wind at the 5.6-km level (shaded colors, $\mathrm{m} \mathrm{s}^{-1}$ ) and total water-ice column (contours, pr. $\mu \mathrm{m}$ ). Three intense jet cores appear in the Alba Patera region (left shaded area in Fig. 5.a), the Deuteronilus-Protonilus Mensae area (lowerright), and Arcadia Planitia (upper-right), and are comparable to the western Pacific, Atlantic and north African jets on Earth. Theoretical analysis by Hollingsworth and Barnes (1996) and Nayvelt et al. (1997) demonstrated that at mid-to-high latitudes, stationary waves were mainly mechanically forced by the Tharsis, Arabia Terra and, to a lesser extent, Elysium ridges, explaining their wavenumber-2 and 3 dominant pattern. Based on momentum conservation, regions where westerlies are accelerated (decelerated) in Fig. 5.a correspond to poleward (equatorward) advection of warm (cold) air masses across the polar front.

Consequently, air parcels are lifted to saturation as they enter and leave the jet cores, and stationary waves thus favor cloud formation in the Acidalia, Utopia and Arcadia basins, as indicated by the arrows in Fig. 5.a. The contribution of the waves to polar hood formation has been quantified by Montmessin et al. (2004), and is apparent from many observations, for instance by James et al. (1996), Wang and Ingersoll (2002) (Fig. 2.g) or Tamppari et al. (2008). 


\subsection{Excursion to $35^{\circ}$ obliquity under clear conditions}

We now step back in geological time and suppose that obliquity is leaning towards an intermediate value of $35^{\circ}$ following an excursion to higher values. As explained in section 2, tropical mountain glaciers can be formed at around $45^{\circ}$ obliquity on the western flanks of the Tharsis volcanoes (Forget et al., 2006). Here we assume that they are the only source of water on the planet, with both polar caps being exhausted. The simulation is thus initialized by placing water-ice reservoirs on the volcanoes (as indicated by red squares in Fig. 7), and by setting the eccentricity and solar longitude of perihelion $L_{p}$ to 0.1 and $270^{\circ}$, respectively. In the first approach, we assume low dust conditions, i.e. $\tau_{\text {dust }}=0.2$.

Under such a scenario, the water cycle is fed by sublimation of the tropical mountain glaciers. This occurs especially when Mars is at perihelion, as illustrated in Fig. 3.b by the appearance of two symmetric 100 pr. $\mu \mathrm{m}$ lobes and increased water vapor column as we approach the northern winter solstice. Many characteristics of the present-day water cycle are conserved, for example the two polar water vapor maxima near solstices, or the Aphelion cloud belt at $\mathrm{L}_{\mathrm{S}}=60-120^{\circ}$. However, a general one order of magnitude increase in water vapor and ice column results from the significant and constant supply by the tropical mountain glaciers, whereas water can only be provided during northern summer under current conditions, and at lower rates. As a result, saturation is reached at much higher temperature, and the hygropause is low- 
ered by several kilometers. A tropical cloud belt is thus formed all year long, as already noted by Mischna et al. (2003), who analyzed the same orbital configuration, but using simplified cloud microphysics and the north polar cap as the only source of water.

This effect is clearly apparent if we focus on the northern winter season, whose zonal-mean atmospheric structure is illustrated in Fig. 4.d. Cross-equatorial Hadley cells are known to be intensified at higher obliquity, due to the increased meridional gradient of surface temperature (Fenton and Richardson, 2001; Haberle et al., 2003). This appears in Fig. 4.d through acceleration of the high-level easterly and low-level westerly jets. Water vapor, as shown in Fig. 4.e, is transported in the ascending branch of the cell, but trapped by early saturation of the parcels in the lowered hygropause region. A thick tropical cloud belt, obvious in Fig. 4.f, thus forms $20 \mathrm{~km}$ below the condensation level we observe today at the same period (Smith, 2002).

Despite the trapping of water vapor in the southern hemisphere, sublimation of the tropical mountain glaciers allows water vapor to be still available at the edge of the polar vortex, as indicated by the bulge of the $2000.10^{-6} \mathrm{~kg} \mathrm{~kg}^{-1}$ contour towards the northern tropics in Fig. 4.e. This creates a secondary cloud belt centered at $30^{\circ} \mathrm{N}$ (see Fig. 4.f), characterized by a water-ice mixing ratio of $300.10^{-6} \mathrm{~kg} \mathrm{~kg}^{-1}$, i.e. two times more than what the model predicts in the Aphelion cloud belt today. Further analysis of this region highlights a wavenumber-3 structure of the cloud belt, linked to the entrance and exit regions of the polar jets and resulting eddy heat fluxes. This relationship is illustrated in Fig. 5.b that shows increased water-ice columns in the lee of the Tharsis, Arabia and Elysium topographic barriers. This resembles the well-known structure of the polar hood borders (Fig. 5.a), that has the same 
dynamical origin.

However, under these past conditions, the latitude at which condensation occurs is moved equatorward by the increased water vapor content of the atmosphere, and advection of water vapor across the polar front by the stationary waves dominates over the simple condensation that occurs in the polar night. A new climate system is thus emerging, in which the main active regions, and possible precipitation, are located in the mid-latitudes, instead of the highlatitudes. Consequently, surface condensation and deposition of fine water-ice crystals extend down to $30^{\circ} \mathrm{N}$ in the regions of enhanced cloud formation, forming seasonal deposits that are up to $1 \mathrm{~mm}$ thick in some areas of the northern mid-latitudes. These paleoclimatic conditions probably represent quiet periods of slow deposition between dusty episodes, thought to be frequent under such obliquity. One further step is thus required to formulate a more realistic scenario.

\subsection{Increasing the dust content of the atmosphere}

As explained earlier, Hadley and monsoon circulation are strengthened as the obliquity increases, probably resulting in frequent dust storms at both solstices (Haberle et al., 2003). Dust cycle modeling under past orbital conditions led Newman et al. (2005) to conclude that "huge amounts of lifting" are already produced at $35^{\circ}$ obliquity. Based on these previous studies, we performed a reference simulation $x_{r e f}$ with a dust opacity of 2.5 , chosen to portray the effect of frequent dust storms on the water cycle. 


\subsubsection{Dust-induced global change:}

The water cycle under dusty conditions is illustrated in Fig. 3.c, and shows water vapor and ice column values that both increase by a factor of $\sim 6$ outside the polar regions compared to the cycle given in Fig. 3.b. A first order explanation lies with the net radiative effect of dust, which is generally to warm the atmosphere above $10 \mathrm{~km}$, because of the large dust opacity at visible compared to infrared (the anti-greenhouse effect). During northern winter, comparison of clear and dusty simulations in the northern mid-latitudes thus reveals a $\sim 10 \mathrm{~K}$ cooling in the first $10 \mathrm{~km}$ of the atmosphere, whereas overlying layers are warmed by up to $40 \mathrm{~K}$. Consequently, in a dusty atmosphere, upper layers and summer hemisphere, through increased saturation vapor pressure, can hold much more water vapor, while the cold lower atmosphere, especially in the winter hemisphere, favors ice nucleation and cloud formation. Activity in the winter hemisphere is thus characterized by a thick cloud belt in the northern mid-latitudes that contrasts with the thin polar night hazes. This mid-latitude cloud belt is revealed in Fig. 3.c by intense condensation between $\mathrm{L}_{\mathrm{S}}=210^{\circ}$ and $\mathrm{L}_{\mathrm{S}}=300^{\circ}$, during which the ice column can be 2 orders of magnitude higher than what exists today on Mars.

What can explain such a large amount of ice in the northern mid-latitudes? Zonal-mean winter circulation, shown in Fig. 4.g, gives further details on the changes induced by dust storm conditions. Warming of the atmosphere is clearly apparent, especially in the southern hemisphere, and results in an even more intense meridional circulation than before, when it was already accelerated by the high obliquity and perihelion conditions. The polar warming, due to adiabatic compression of air parcels in the subsiding branch of the Hadley cell (Wilson, 1997; Forget et al., 1999), produces a large inversion that ex- 
tends up to the north pole. The low-level westerly jet is two times faster than today, and is thought to play the main role in lifting dust and warming the southern hemisphere, as shown for example by Newman et al. (2005) or Basu et al. (2006). Finally, the polar vortex is significantly weakened under dusty conditions, as already noticed by Newman et al. (2002), for dynamical reasons that are beyond the scope of this paper, but possibly related to the intense polar warming. These changes in atmospheric thermodynamics have a wide range of impacts on the water cycle.

Warming of the southern hemisphere elevates the hygropause $20 \mathrm{~km}$ higher than the previous simulation, and allows water vapor to be transported from the equatorial reservoir to the intense upwelling zone of the Hadley cell, and up to the upper atmosphere (see the first water vapor maximum around $50^{\circ} \mathrm{S}$ on Fig. 4.h). Then, a large part of this water vapor crosses the equator and builds up along the polar vortex (second maximum around $30^{\circ} \mathrm{N}$ on Fig. 4.h), while another part condenses out to form a thin high-altitude cloud belt centered on the equator, and apparent in Fig. 4.i. Around $10 \mathrm{~g} \mathrm{~kg}^{-1}$ of water vapor thus reaches the polar front, and is available for cloud formation.

[Fig. 6 about here.]

\subsubsection{The mid-latitude cloud belt:}

Meanwhile, winter eddy circulation starts in the northern mid-latitudes, and controls the cross-front mixing of moisture. The structure of the stationary waves is clearly modified compared to non-dusty conditions, as illustrated in Fig. 5.c. While the Tharsis jet strength remains nearly unchanged with more than $30 \mathrm{~m} \mathrm{~s}^{-1}$ zonal wind speed, Arabia and Elysium jets damp down to 25 and 
$20 \mathrm{~m} \mathrm{~s}^{-1}$ respectively. The acceleration pattern of Elysium is mainly preserved, whereas a southwest-northeast oriented jet now covers the northern part of Arabia Terra, before being abruptly decelerated in Utopia Planitia. Figure 6 gives details on this winter circulation, and represents a horizontal wind field at the $5.6 \mathrm{~km}$ level, superposed on the atmospheric water-ice column in pr. $\mu \mathrm{m}$.

The wavenumber-3 jet structure is clearly pronounced in the northern midlatitudes, and the jet is far from zonal, as opposed to clear conditions. Poleward motion of the flow peaks over Deuteronilus Mensae, Phlegra Montes and the western flank of Alba Patera, reaching a meridional velocity of $\sim 8 \mathrm{~m} \mathrm{~s}^{-1}$ at the $5.6 \mathrm{~km}$ level, whereas Amazonis, Chryse and Utopia basins are regions of equatorward motion, with meridional speed up to 6,10 and $16 \mathrm{~m} \mathrm{~s}^{-1}$, respectively. The largest modification occurs in Deuteronilus Mensae, where the flow was almost exclusively zonal under non-dusty conditions. Barnes et al. (1996) noticed similar trends under current orbital conditions by increasing dust opacity from 0.3 to 2.5 , and found strong meridional acceleration over Deuteronilus and Elysium at the $\sim 18 \mathrm{~km}$ level (Barnes et al. (1996), Fig. 19), with an increase in wavenumber 2 amplitude. Interestingly, TES observed the same increased wave 2 amplitude at $45^{\circ} \mathrm{E}$ (Banfield et al. (2003), Fig. 10) during winter, which corresponds again to the Deuteronilus-Protonilus region. Hollingsworth and Barnes (1996) also observed a tendency of wavenumber 2 to be "squashed" in mid-latitudes as dust content is increased, with "larger poleward momentum flux" south of $45^{\circ} \mathrm{N}$. According to Nayvelt et al. (1997), low-level eddy circulation north and south of $45^{\circ} \mathrm{N}$ is dominated by mechanical and radiative forcing of topography, respectively (Fig. 10.a of Nayvelt et al. (1997)). Comparing this with Fig. 6, it appears that the eddy flux north of the 150 pr. $\mu \mathrm{m}$ white line is mainly mechanically forced, while the largest water 

611 (Marchant and Head, 2007). plateaus.

vapor advection south of this line is due to the radiative forcing response, for instance in Amazonis and Chryse Planitia, north of Syrtis Major, as well as on each side of Elysium. Heat flux and resulting condensation thus seem to be mainly controlled by radiative forcing of stationary waves in mid-latitudes. Furthermore, this forcing is enhanced by the stronger inversion that occurs in the lower dusty atmosphere, which results in larger lateral temperature gradients, with low-lying regions up to $20 \mathrm{~K}$ colder at $45^{\circ} \mathrm{N}$ than the surrounding

Clouds are thus located along the zonally symmetric water vapor gradient (white lines in Fig. 6) in these regions of large eddy activity, and appear in both Fig. 5.c and 6 as opaque cloud covers in Tempe Terra, west and east of Amazonis Planitia, and in a southwest-northeast oriented zone, from western Arabia to Utopia. The water-ice column attains 800 pr. $\mu \mathrm{m}$, which is two orders of magnitude thicker than the current Aphelion cloud belt. Low-level condensation processes create ice crystals more than $7 \mu \mathrm{m}$ in radius in the northern mid-latitudes, similar to the largest particle predicted in the Polar Hood on present-day Mars (Montmessin et al., 2004). Under these conditions, mean annual precipitation in some regions of the mid-latitudes is of the order of $10 \mathrm{~mm} \mathrm{yr}{ }^{-1}$, with surface temperature around $-75^{\circ} \mathrm{C}$. This is clearly different from the non-dusty simulation, where only transient snow deposits of a few micrometers were present. Here, ice is accumulating at a pace that could lead to regional ice sheet formation, with precipitation and temperature that correspond to inferred conditions of the last glacial maximum in Antarctica 


\section{Accumulation rates and dependence on climate parameters}

\subsection{Annual water-ice budget}

Glaciers represent an equilibrium between winter precipitation and summer sublimation. Precipitation and accumulation of ice during winter are not sufficient to produce glaciers, whose distribution thus depends on summer sublimation, and to first order on summer peak temperatures (the dominant term of Eq. 1). The upper panel of Fig. 7 illustrates the net annual snow accumu-

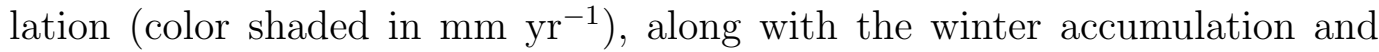
summer sublimation rates in the lower left and lower right panel, respectively. Model predictions are superposed on the map by Squyres (1979), which shows the specific location of several different types of ice-related features (see also Fig. 1).

[Fig. 7 about here.]

Three main regions of winter precipitation clearly appear in Fig. 7.b. One area of enhanced winter precipitation occurs around Alba Patera (west, north and east), then a second one north of Arabia Terra in the Deuteronilus-Protonilus Mensae region and, finally, a third one between the Tharsis and Elysium rises. All three of these regions correspond to the largest concentration of ice-related landforms noticed by Squyres (1979), and concentrations of glacial landforms mapped by Head and Marchant (2006) (see Fig. 1).

Seasonal variations of surface ice deposits in four different regions pointed out in Fig. 7 are represented in Fig. 8, and clearly show constant precipitation during winter, with a period of enhanced accumulation (represented by the 
second shaded region) at the beginning of this season. A detailed analysis of this period reveals the passing of low pressure systems due to baroclinic waves, with precipitation events of around $10 \mu \mathrm{m}$. Associated cold fronts and surface temperature variations are seen in the lower panel of Fig. 8. These waves, stabilized by the topographic high of the dichotomy boundary, could play a major role in the mid-latitude glaciation, because they also result in the formation of dust storms. Large weather systems could therefore arise from these local dust storms, propagating along the dichotomy boundary and creating ideal conditions for nucleation of ice crystals on dust nuclei over glacial regions.

[Fig. 8 about here.]

Winter deposits are only preserved on the northern flank of Alba Patera and along the scarp of the Deuteronilus-Protonilus region, while the others, north of Olympus Mons and on the uplands of DPM, are lost by summer sublimation (see Fig. 7.c). This sublimation is also visible in Fig. 8, and highlighted by the first shaded region. Interestingly, ice builds up even during summer in Nilosyrtis Mensae and Phlegra Montes (lines \# 3 and 4), where precipitation is brought by the dry western boundary currents that meet humid air masses of the northern summer. Otherwise, summer sublimation explains why the net annual accumulation regions in Fig. 7.a do not only reflect winter precipitation (see the cloud cover of Fig. 6), but also summer peak temperatures and resulting sublimation. These surface temperatures are controlled by, in order of decreasing impact, thermal inertia, albedo, local slope, atmospheric dust and altitude. In this simulation, our model only accounts for dust and altitude effects, with an arbitrary change in surface albedo when ice is present. Thermal inertia is equal to current observed values, and its changes induced 
by deposition of ice on the surface is considered in section 5.3. Atmospheric dust reduces diurnal temperature variations by producing lower short-wave fluxes during the day and increased long-wave fluxes during the night, and induces in most cases mean surface cooling of the summer mid-latitudes. Consequently, dust storm conditions not only favor winter precipitation, but also reduce summer sublimation.

Altitude has a very small impact on surface temperature due to the low density of the atmosphere. This is in sharp contrast to the terrestrial case, in which glaciers flow down into lower and warmer environments, and undergo melting or sublimation. Mars glaciology might be significantly different than that of the Earth, with an unexpected glacier mass balance due to changes in equilibrium line approach, as mentioned in Fastook et al. (2008). Sublimation dependence on elevation not only involves temperature, but also water vapor circulation and resulting humidity found in glacial valleys. These questions are being addressed using mesoscale atmospheric modeling and glacial modeling (Fastook et al., 2009).

It is worth noting that ice also builds up in Valles Marineris, Terra Meridiani and southern Elysium (see Fig. 7.a). However, these regions have a relatively high thermal inertia, which often results in lower summer sublimation, and this forcing could bias our results, as thermal inertia has probably varied through the Amazonian. To assess this effect, we set the thermal inertia and albedo to $217 \mathrm{~J} \mathrm{~s}^{-1 / 2} \mathrm{~m}^{-2} \mathrm{~K}^{-1}$ and 0.23 everywhere on Mars, which correspond to planetary mean values, and reran the reference simulation. Interestingly, the ice distribution of Fig. 7 remains broadly unchanged in the northern mid-latitudes, confirming that winter atmospheric precipitation controlled by topography is the main accumulation process. However, accumulation rates 
in Terra Meridiani and southern Elysium are reduced to a few millimeters, and ice disappears in Valles Marineris. This suggests that present-day thermal inertia was the main cause of preferential accumulation in these regions. Consequently, despite potentially interesting, we cannot further comment on these deposits in the present state of our model.

\subsection{Sensitivity to climate parameters}

The way glaciers are affected by perturbations in climate parameters is crucial to understanding their geologic history, and the relationship between orbital forcing and glacial stratigraphy. Following the orbital calculations of Laskar et al. (2004), we address this issue by disturbing the reference conditions (i.e. the ones leading to the glaciation of Fig. 7) and analyzing changes in precipitation activity and ice preservation. We will also study the impact of changing thermal inertia as the surface is being covered with ice.

Results are summarized in Table 1 , that will be used to monitor water-ice reservoir and atmospheric response to different forcings, and in Fig. 9, that illustrates the different accumulation rates obtained for each sensitivity experiment.

[Table 1 about here.]

[Fig. 9 about here.] 

722 is underway to assess this effect.

\subsubsection{The dust cycle: Main actor in the glaciation}

As underlined in section 4, increased atmospheric dust content is the key factor allowing the initiation of the northern glaciation, by increasing water vapor holding capacity, moving the saturation region to lower latitudes, and favoring stationary waves. Consequently, when we increase the dust opacity in simulations $x_{3}, x_{4}$ and $x_{r e f}$, source sublimation rises and the meridional component of the $5.6 \mathrm{~km}$ wind, which is a good indicator of stationary wave activity, strengthens. Atmospheric water vapor and ice columns at $45^{\circ} \mathrm{N}$, which reflect precipitation activity, reveal the same tendency. Interestingly, once dust opacity has reached 1.5, few changes are observed in winter accumulation rates compared to maximum dust conditions. However, large changes in annual accumulation rates are observed between Fig. 9.e $\left(\tau_{\text {dust }}=1.5\right)$ and Fig. 9.a $\left(\tau_{\text {dust }}=2.5\right)$ because the higher dust opacity cools the daytime lower atmosphere during summer, and favors ice preservation. But we have to remember that clouds are radiatively inactive in these experiments, and might play the same role by cooling daytime surface temperatures (Wilson et al., 2007). Work

\subsubsection{Obliquity range: effect on ice preservation}

If we maintain optimal conditions and only change the obliquity, glaciation occurs for an obliquity between $15^{\circ}$ and $35^{\circ}$, as seen in Fig. 9.a,b,c. As obliquity is decreased, a larger fraction of the insolation goes to the equatorial region, and sublimation of the equatorial reservoirs is enhanced, as clearly seen in Table 1. Finally, stationary waves and precipitation remain active, even though a decrease of the water-ice column is observed at $15^{\circ}$ obliquity, due to much 

$751 \quad\left(25-35^{\circ}\right)$ obliquity periods. in Table 1.

higher atmospheric temperatures in northern mid-latitudes during winter.

However, $45^{\circ}$ obliquity leads to a sharp change in the winter circulation pattern and to a large increase of summer surface temperatures. At this obliquity, the largest fraction of insolation falls in the mid-latitudes during summer, and prevents any ice preservation, as seen in Fig. 9.f. Attenuation of stationary planetary waves and baroclinic activity also reduces winter precipitation, as revealed by a slight decrease in the wind speed, water vapor and ice columns

The $15^{\circ}$ obliquity simulation $\left(x_{1}\right)$ may be unrealistic, because the atmospheric dust opacity during periods of low obliquity is not expected to be so high $\left(\tau_{\text {dust }}=2.5\right)$, even though dust lifting is favored by the baroclinic activity (Haberle et al., 2003). However, knowing that under current orbital conditions, a dust opacity of 2.5 is possible at regional scales during perihelion dusty season, simulation $x_{2}$ might be a reasonable scenario. Indeed, we assume that Mars returns from a high obliquity excursion at $\sim 45^{\circ}$, during which tropical mountain glaciers have been formed, and approaches orbital conditions similar to current ones. In this case, regional dust storms, coupled with increased moisture levels due to the equatorial water sources, might have been sufficient to bring precipitation in the northern mid-latitudes. Finally, $x_{r e f}$ conditions were probably common in the past. Therefore, we suggest that geological periods favorable for glacial activity were probably intermediate 


\subsubsection{Changing the perihelion: an interglacial period}

The mid-latitude glaciation is also very sensitive to a change of eccentricity, and a decreasing eccentricity results in a retreat, or suppression of the deposits (see Fig. 9.g). The next to last simulation of Table 1 shows the effect of a null eccentricity on the $35^{\circ}$ obliquity simulation. Precipitation is still active, despite the weakening of the atmospheric circulation, but warmer surface temperatures result in the sublimation of most of the mid-latitude ice during summer. However, some deposits remain stable near Nilosyrtis Mensae and Phlegra Montes. All in all, high eccentricity $(\sim 0.1)$ seems necessary for a large extension of the mid-latitude glaciation, and periods of low eccentricity might be interglacial periods, where a retreat of the glaciers is likely to occur.

The argument of perihelion is also essential, and a reversed $\operatorname{argument} \mathrm{L}_{\mathrm{p}}=90^{\circ}$ (see Fig. 9.h) also results in a retreat of the northern mid-latitude deposits. However, as noticed by Mischna et al. (2003), ice then tends to be stable in aphelion summer hemisphere. Figure 9.h thus reveals many interesting deposition patterns in the southern mid-latitudes, further represented in Fig. 10. Net accumulation of ice predicted by the LMD/GCM is compared to the icerelated landforms mapped by Squyres (1979). Two deposition regions of the model are located south of Argyre Planitia (arrow 1.) and around western Hellas (arrow 2.), and are in good agreement with the observations. Interestingly, no accumulation is predicted in the glacial region of eastern Hellas, which is discussed in Forget et al. (2006), and results from other orbital conditions (see section 2.3). A large deposition belt is also present at $50^{\circ} \mathrm{S}$, between $120^{\circ} \mathrm{E}$ and $120^{\circ} \mathrm{W}$, in regions where no glacial landforms have been mapped by Squyres (1979). A further analysis is beyond the scope of this paper, even though this high precipitation belt might be geologically relevant. 
This broad deposition pattern of the southern hemisphere gives support to the idea that mid-latitude glaciation occurs in both hemispheres under dusty and intermediate obliquity conditions $\left(\sim 35^{\circ}\right)$, assuming an equatorial water source. Glaciation is then favored in the northern or southern hemisphere, depending on the solar longitude of perihelion.

\subsection{Impact of thermal-inertia feedback}

Thermal inertia is a composite quantity defined as $I=\sqrt{\lambda C}$ in $\mathrm{J} \mathrm{s}^{-1 / 2} \mathrm{~m}^{-2} \mathrm{~K}^{-1}$, where $C$ is the volumetric heat capacity, and $\lambda$ the thermal conductivity, the latter undergoing the largest variations among different geological materials. In all the simulations presented above, thermal inertia was based on the IRTM and TES observations (Forget et al., 1999), and we assumed that the surface thermal inertia was not affected by the presence of ice. This assumption holds for a seasonal micrometer-sized frost that is too thin to have an impact on surface and subsurface temperatures. Consequently, under current climatic conditions, this assumption is always valid. However, it does not hold for cmsized ice layers stable at depth or draped over the regolith.

To assess this effect, we have taken advantage of a new conduction model that solves the unsteady heat diffusion equation on 18 fixed vertical grid points of varying thermal inertia. As a first approach, we use the 1-D version of the LMD/GCM to assess the impact on surface temperatures generated by an ice layer of different thicknesses (x-axis of Fig. 11) deposited on top of a regolith of varying thermal inertia (y-axis). The model is run at $45^{\circ} \mathrm{N}$ with 
the $x_{r e f}$ climate parameters (see Table 1), assuming a volumetric heat capacity $C$ of $10^{6} \mathrm{~J} \mathrm{~m}^{-3} \mathrm{~K}^{-1}$, an ice albedo of 0.4 , and an ice thermal inertia of $1000 \mathrm{~J} \mathrm{~s}^{-1 / 2} \mathrm{~m}^{-2} \mathrm{~K}^{-1}$, which is an intermediate value between the 600 and $2000 \mathrm{~J} \mathrm{~s}^{-1 / 2} \mathrm{~m}^{-2} \mathrm{~K}^{-1}$ water-ice deposits observed in the north polar region by Paige et al. (1994).

[Fig. 11 about here.]

Figure 11 represents the obtained annual mean and maximum surface temperatures. Increasing thermal inertia decreases the diurnal temperature range, resulting in a drop of maximum temperatures in Fig. 11 when the ice thickness exceeds $1 \mathrm{~cm}$. Such an abrupt collapse of annual maximum temperatures would prevent the ice from sublimating during summer, and would give rise to a positive feedback. However, since daily temperature changes are reduced, less infrared radiation is lost during the day and on annual mean basis, the surface is warmed up by several degrees, as seen in Fig. 11 and already noticed by Paige (1992). Does this feedback accelerate or decelerate the growth of the ice sheet?

To answer this question, we allow the thermal inertia of the subsurface to vary in the GCM as a function of ice thickness, and rerun the reference simulation ( $x_{r e f}$ in Table 1$)$. As observed in previous sections, ice is deposited in the northern mid-latitudes, forming a layer of high thermal inertia that is more than $1 \mathrm{~cm}$ thick after 3 years of simulation. From then on, summer peak temperatures begin to cool, thereby decreasing sublimation until the ice thickness reaches $\sim 5 \mathrm{~cm}$ after 10 years of simulation, at which point summer sublimation almost disappears and peak temperatures stabilize at $\sim 230 \mathrm{~K}$ (compared 25 to $\sim 250 \mathrm{~K}$ without the ice) in Deuteronilus Mensae. Consequently, thermal 
851 et al., 2006). Fig. 12.c).

inertia feedback does accelerate the growth of the ice layer, but only up to a certain point where a maximum accumulation rate is reached. In the glacial regions, the annual accumulation rate is in this case only about $20 \%$ higher than for the reference simulation (see Fig. 12.a).

However, extending the thermal inertia feedback to the equatorial water-ice sources has a significant impact in our simulations on the accumulation rates. Indeed, peak temperatures of the sources are decreased by their high thermal inertia, and annual sublimation plummets from dozens of $\mathrm{cm}$ (see Table 1) to $\sim 5 \mathrm{~mm}$, providing less water to the climate system. Consequently, the atmospheric water vapor amount goes down from $\sim 300$ pr. $\mu \mathrm{m}$ to $\sim 100$ pr. $\mu \mathrm{m}$ on average, bringing less precipitation to the mid-latitudes and a winter snow cover of only $\sim 3 \mathrm{~mm}$ thickness, that almost completely sublimates away during summer (see Fig. 12.b). If we now suppose that albedo of the tropical mountain glaciers is lower than the previously used value of 0.4 due to the debris cover (Marchant and Head, 2007), and equal to 0.2, atmospheric water vapor is restored, and a seasonally persistent snow cover is again predicted, especially in glacial regions where accumulation can reach $\sim 10 \mathrm{~mm} \mathrm{yr}^{-1}$ (see

These results show that thermal inertia feedback has a large impact on surface temperatures and ice sublimation, and may be able to prevent sublimation during interglacial periods, thereby sequestering the ice in the mid-latitudes over a significant amount of time. They also emphasize the large dependence of the water cycle on physical processes that occur in the multiple sources. For example, refined understanding of the TMG sublimation process, as seen above, will be crucial to improve the modeling of martian ice ages (Kowalewski 


\title{
6 Discussion
}

\begin{abstract}
The good agreement of our simulations with the geological observations, the orbital constraints given by the sensitivity studies of section 5.2 , and the approximate ages of the glacial landforms allow us to propose an updated scenario for the Martian Ice Ages. We suppose for clarity that we start from a past Martian climate similar to the one observed today that would occur during a high mean obliquity period $\left(25-45^{\circ}\right)$.
\end{abstract}

A first increase in obliquity results in the sublimation of the north polar cap, and formation of tropical mountain glaciers with an accumulation rate up to $\sim 60 \mathrm{~mm} \mathrm{yr}^{-1}$ under $45^{\circ}$ (or more) obliquity (Levrard et al., 2004; Forget et al., 2006). As we neglect the effect of a dust lag on the sublimation of the sources (Mischna and Richardson, 2005), these accumulation rates can be seen as optimal. This also applies to the mid-latitude glaciation predicted here.

After this excursion, obliquity falls to around $35^{\circ}$. Given the high dust content of the atmosphere under these conditions (Newman et al., 2005) and the presence of tropical mountain glaciers, an increased water cycle results in large mid-latitude precipitation controlled by strong stationary planetary waves. Wavenumber 3 favors the accumulation of snow in glacial regions, including the Deuteronilus-Protonilus Mensae fretted terrains (Head et al., 2006a,b), and results in the formation of a regional ice sheet. The climate system can sustain mid-latitude glaciation by staying in the $25-35^{\circ}$ obliquity range given in section 5.2, until a new high obliquity $\left(\sim 45^{\circ}\right)$ excursion occurs. The cor- 
responding period of time of approximately 50 ky creates, if we suppose accumulation rates around $10-20 \mathrm{~mm} \mathrm{yr}^{-1}$ (see Table 1), an ice sheet of up to 500-1000 m thickness. At the end of this period, if we consider that a lower dust opacity is likely to occur when the obliquity is only $25^{\circ}$, some simulations suggest that the precipitation is still active, but with decreased accumulation of $\sim 1-2 \mathrm{~mm} \mathrm{yr}^{-1}$ and increased sublimation during the summer. This lower regime of glaciation might explain the formation of superposed lobate debriscovered glaciers described by Levy et al. (2007) and Dickson et al. (2008). The mid-latitude glaciation, based on the age of the lobate debris aprons, might have lasted for several hundreds of Myr, and some deposits may be as young as $\sim 10$ Myr (Mangold, 2003). The remnants we see today thus represent the signature of a recent glacial event, whose ice has been preserved under a sublimation till, as confirmed by radar sounding (Plaut et al., 2009). Age of the tropical mountain glaciers is estimated to be 10-200 Myr (see section 2), confirming that the mid-latitude and tropical glacial activities occurred during the same geological period.

The $25-35^{\circ}$ obliquity period is also favorable for the formation of a mantle that is draped over the high latitudes, and visible in Fig. 9.a,b,c,e. These deposits may have contributed to the formation of the latitude dependent mantle (see section 2) under higher obliquity conditions than those observed by Levrard et al. (2004). However, increasing number of observations point to an extremely young age of the latitude dependent mantle $(\sim 0.1 \mathrm{Myr}$, see Head et al. (2003); Kostama et al. (2006)), that might have formed during the current low mean obliquity period, at epochs where the equatorial water sources were likely depleted. Consequently, its climatic origin is not yet clearly established. 
As we start a new high obliquity excursion $\left(\sim 45^{\circ}\right)$, the mid-latitude deposits, as well as the high-latitude mantle, might sublimate away and feed the tropical mountain glaciers again. In that case, the water cycle would be closed, and a high mean obliquity period would be characterized by the oscillations of the ice reservoirs between the tropical mountain glaciers and the mid-to-high latitude deposits, producing consistent stratigraphy in both deposits.

It is worth noting that the mid-latitude glacial activity might also be sustained by the south polar cap, or any other source able to provide enough water vapor to the winter atmosphere. At the moment, from a modeling point of view, an equatorial water source is necessary, but improvements of the GCM may change this result.

\section{Conclusions}

A climatic origin for the Amazonian northern mid-latitude glaciation is explored using the LMD Global Climate Model, and the main findings can be summarized as follows:

(1) Formation of an ice sheet is predicted by the LMD/GCM in the northern mid-latitudes during periods of moderate obliquity by 1) sublimation of an equatorial water source, 2) increased dust content and water vapor holding capacity of the atmosphere, 3) resulting migration of the saturation zone from high to mid-latitudes, 4) poleward flux of water vapor controlled by strong stationary planetary waves and transient weather systems, 5) condensation and precipitation of water ice to form a thick cloud belt in the northern mid-latitudes, 6) deposition of ice in glacial 
regions, 7) differential sublimation and erosion of the deposits during northern summer and preservation in glacial regions;

(2) Longitudinal distribution of the deposits in the $30-50^{\circ} \mathrm{N}$ band results from the wavenumber-3 structure of the stationary planetary waves and topographic forcing induced by the Tharsis, Arabia, and Elysium barriers;

(3) Based on climate sensitivity experiments, glaciation is found to occur during moderate obliquity periods, and requires an equatorial water source (here assumed to be the tropical mountain glaciers), an obliquity of 25$35^{\circ}$, a high eccentricity $(\sim 0.1)$, an aphelion season corresponding to northern summer $\left(\mathrm{L}_{\mathrm{p}}=270^{\circ}\right)$, and a high dust opacity $\left(\tau_{\text {dust }}>1.5\right)$. Such conditions probably occurred many times during the estimated period of glaciations ( 10-300 Myr, Mangold (2003));

(4) Predicted accumulation rates of $\sim 10-20 \mathrm{~mm} \mathrm{yr}^{-1}$ are consistent with the formation of regional ice sheets, and have large implications for the recent history of the water cycle. Glacial activity in the mid-latitudes involves a significant amount of water and should thus appear as a major component of the global stratigraphy. GCM simulations point to the importance of dust for controlling the water vapor holding capacity of the atmosphere, and suggest a complex coupling between the dust content of the atmosphere and the glacial activity of the planet, as also observed on Earth (Harrison et al., 2001; Lambert et al., 2008).

(5) Thermal inertia feedback caused by surface water-ice results in a progressive lowering of summer peak temperatures in the glacial regions, and can lead to disappearance of the summer sublimation phase. This result of the climate model suggests that ice might be preserved and sequestered over long periods of time by the impact of ice thermal inertia on surface temperatures. 
[Fig. 13 about here.]

Figure 13 illustrates the different components of the climate system controlling the northern mid-latitude glaciation. Dashed arrows represent major feedbacks that still need to be constrained and implemented into the LMD/GCM. These include:

- Radiative effect of clouds, today but also under past conditions where clouds reach significant optical depth and spatial coverage;

- Radiative effect of water vapor, that is neglected on present-day Mars, but may influence our results under past conditions, given the high water vapor holding capacity of the atmosphere;

- Dust lifting and coupling with the cloud microphysics, as well as scavenging of dust by water-ice particles;

- Coalescence of ice crystals induced by high precipitation events;

- Physics of the ice deposits: latent heat exchange induced by sublimation or melting of the deposits, heating within the ice layer by absorption of solar radiation (Clow, 1987), and the protective effect of a dust lag (Mischna and Richardson, 2005).

The detailed analysis of the mid-latitude geomorphology, in light of terrestrial analogs and new data from the Mars Reconnaissance Orbiter mission, is continuing to provide major insights into the microclimate and water budget of the glacial systems. A comparison of these detailed observations with GCM and mesoscale predictions (Spiga and Forget, 2009) will certainly improve our knowledge of the glacial climate.

We are just beginning to understand the main components of this complex climate signal. Hundreds of millions of years of glacial-interglacial climate is 
recorded in the extremely well-preserved martian stratigraphy. Mars is the only opportunity at hand to explore a climate system similar to the terrestrial glacial ages, and to test our understanding of the fundamental feedbacks controlling climate changes on Earth.

\section{Acknowledgements}

The LMD Martian global climate model has been developed with the support of CNRS, European Space Agency (ESA), and CNES in collaboration with the Atmospheric, Oceanic, and Planetary Physics group in Oxford University (UK). We thank A. Spiga, N. Mangold, T. Fouchet and all our colleagues at LMD for inspiration and advice. This work was also performed while J-B.M. was visiting the Planetary Geosciences Group in the Department of Geological Sciences of Brown University, in collaboration with the TAO Department of ENS Paris. We are grateful to A. Côté, N. Christy, J. Dickson, C.I. Fassett, M.A. Kreslavsky, J. Levy, G.A. Morgan, and the team of the Center for Computation and Visualization (CCV) for fascinating discussions and support. J-B.M. thanks UPMC (Université Pierre et Marie Curie) for doctoral fellowship. J.W.H. thanks the NASA Mars Data Analysis Program for support. We are finally grateful to R.M. Haberle and an anonymous reviewer for their detailed and essential comments, and to the editorial team of Icarus for manuscript preparation and publication.

\section{References}

Angelats i Coll, M., Forget, F., López-Valverde, M. A., González-Galindo, F., 
Feb. 2005. The first Mars thermospheric general circulation model: The Martian atmosphere from the ground to $240 \mathrm{~km}$. Geophysical Research Letters 32, L04201.

Armstrong, J. C., Leovy, C. B., Quinn, T., Oct. 2004. A 1 Gyr climate model for Mars: new orbital statistics and the importance of seasonally resolved polar processes. Icarus 171, 255-271.

Banfield, D., Conrath, B. J., Smith, M. D., Christensen, P. R., Wilson, R. J., Feb. 2003. Forced waves in the martian atmosphere from MGS TES nadir data. Icarus 161, 319-345.

Barnes, J. R., Haberle, R. M., Pollack, J. B., Lee, H., Schaeffer, J., 1996. Mars atmospheric dynamics as simulated by the NASA Ames general circulation model 3. Winter quasi-stationary eddies. Journal of Geophysical Research 101, 12753-12776.

Basu, S., Wilson, J., Richardson, M., Ingersoll, A., Sep. 2006. Simulation of spontaneous and variable global dust storms with the GFDL Mars GCM. Journal of Geophysical Research (Planets) 111, E09004.

Bibring, J.-P., 10 colleagues, Mar. 2005. Mars Surface Diversity as Revealed by the OMEGA/Mars Express Observations. Science 307, 1576-1581.

Bibring, J.-P., 12 colleagues, the OMEGA team, Apr. 2004. Perennial water ice identified in the south polar cap of Mars. Nature 428, 627-630.

Böttger, H. M., Lewis, S. R., Read, P. L., Forget, F., Sep. 2005. The effects of the martian regolith on GCM water cycle simulations. Icarus 177, 174-189.

Clancy, R. T., Grossman, A. W., Wolff, M. J., James, P. B., Rudy, D. J., Billawala, Y. N., Sandor, B. J., Lee, S. W., Muhleman, D. O., Jul. 1996. Water vapor saturation at low altitudes around Mars aphelion: A key to Mars climate? Icarus 122, 36-62.

Clow, G. D., Oct. 1987. Generation of liquid water on Mars through the melt- 
ing of a dusty snowpack. Icarus $72,95-127$.

Crown, D. A., Price, K. H., Greeley, R., Nov. 1992. Geologic evolution of the east rim of the Hellas basin, Mars. Icarus 100, 1-25.

Dickson, J., Head, J. W., Marchant, D. R., May 2008. Late Amazonian glaciation at the dichotomy boundary on Mars: Evidence for glacial thickness maxima and multiple glacial phases. Geology 36 (5), 411-414.

Fastook, J. L., Head, J. W., Madeleine, J.-B., Forget, F., Marchant, D. R., Mar. 2009. Modeling Northern Mid-Latitude Glaciation with GCM-driven Climate: Focus on Deuteronilus-Protonilus Mensae Valleys. In: 40th Lunar and Planetary Institute Science Conference. Vol. Abstract 1144.

Fastook, J. L., Head, J. W., Marchant, D. R., Forget, F., Dec. 2008. Tropical mountain glaciers on Mars: Altitude-dependence of ice accumulation, accumulation conditions, formation times, glacier dynamics, and implications for planetary spin-axis/orbital history. Icarus 198, 305-317.

Fenton, L. K., Richardson, M. I., Dec. 2001. Martian surface winds: Insensitivity to orbital changes and implications for aeolian processes. Journal of Geophysical Research 106, 32885-32902.

Forget, F., Apr. 1998. Improved optical properties of the Martian atmospheric dust for radiative transfer calculations in the infrared. Geophysical Research Letters 25, 1105-1108.

Forget, F., Haberle, R. M., Montmessin, F., Levrard, B., Head, J. W., Jan. 2006. Formation of Glaciers on Mars by Atmospheric Precipitation at High Obliquity. Science 311, 368-371.

Forget, F., Hourdin, F., Fournier, R., Hourdin, C., Talagrand, O., Collins, M., Lewis, S. R., Read, P. L., Huot, J.-P., Oct. 1999. Improved general circulation models of the Martian atmosphere from the surface to above 80 km. Journal of Geophysical Research 104, 24155-24176. 
Forget, F., Hourdin, F., Talagrand, O., Feb. 1998. CO2 Snowfall on Mars: Simulation with a General Circulation Model. Icarus 131, 302-316.

Fouchet, T., 10 colleagues, Sep. 2007. Martian water vapor: Mars Express PFS/LW observations. Icarus 190, 32-49.

Haberle, R. M., McKay, C. P., Schaeffer, J., Joshi, M., Cabrol, N. A., Grin, E. A., Mar. 2000. Meteorological Control on the Formation of Martian Paleolakes. In: 31st Lunar and Planetary Institute Conference. p. Abstract 1509.

Haberle, R. M., Murphy, J. R., Schaeffer, J., Jan. 2003. Orbital change experiments with a Mars general circulation model. Icarus 161, 66-89.

Haberle, R. M., Pollack, J. B., Barnes, J. R., Zurek, R. W., Leovy, C. B., Murphy, J. R., Lee, H., Schaeffer, J., Feb. 1993. Mars atmospheric dynamics as simulated by the NASA AMES General Circulation Model. I - The zonalmean circulation. Journal of Geophysical Research 98, 3093-3123.

Harrison, S. P., Kohfeld, K. E., Roelandt, C., Claquin, T., Jun. 2001. The role of dust in climate changes today, at the last glacial maximum and in the future. Earth-Science Reviews 54 (1-3), 43-80.

Head, J. W., 12 colleagues, Co-Investigator Team, Mar. 2005. Tropical to midlatitude snow and ice accumulation, flow and glaciation on Mars. Nature 434, 346-351.

Head, J. W., Marchant, D. R., Jul. 2003. Cold-based mountain glaciers on Mars; western Arsia Mons. Geology 31 (7), 641-644.

Head, J. W., Marchant, D. R., Mar. 2006. Evidence for Global-Scale Northern Mid-Latitude Glaciation in the Amazonian Period of Mars: Debris-covered Glacier and Valley Glacier Deposits in the $30-50^{\circ} \mathrm{N}$ Latitude Band. In: 37th Annual Lunar and Planetary Science Conference. p. Abstract 1127.

Head, J. W., Marchant, D. R., Mar. 2008. Evidence for Non-Polar Ice Deposits 
in the Past History of Mars. In: 39th Annual Lunar and Planetary Science Conference. p. Abstract 1295 .

Head, J. W., Marchant, D. R., Agnew, M. C., Fassett, C. I., Kreslavsky, M. A., Jan. 2006a. Extensive valley glacier deposits in the northern mid-latitudes of Mars: Evidence for Late Amazonian obliquity-driven climate change. Earth and Planetary Science Letters 241, 663-671.

Head, J. W., Mustard, J. F., Kreslavsky, M. A., Milliken, R. E., Marchant, D. R., Dec. 2003. Recent ice ages on Mars. Nature 426, 797-802.

Head, J. W., Nahm, A. L., Marchant, D. R., Neukum, G., Mar. 2006b. Modification of the dichotomy boundary on Mars by Amazonian mid-latitude regional glaciation. Geophysical Research Letters 33, L08S03.

Herkenhoff, K. E., Byrne, S., Russell, P. S., Fishbaugh, K. E., McEwen, A. S., Sep. 2007. Meter-Scale Morphology of the North Polar Region of Mars. Science 317, 1711-1715.

Hollingsworth, J. L., Barnes, J. R., Aug. 1996. Forced stationary waves in Mars winter atmosphere. Journal of the Atmospheric Sciences 53 (3), 428-447.

Houben, H., Haberle, R. M., Young, R. E., Zent, A. P., Apr. 1997. Modeling the Martian seasonal water cycle. Journal of Geophysical Research 102, 9069-9084.

Hourdin, F., Armengaud, A., May 1999. The Use of Finite-Volume Methods for Atmospheric Advection of Trace Species. Part I: Test of Various Formulations in a General Circulation Model. Monthly Weather Review 127 (5), 822-837.

Hourdin, F., Le van, P., Forget, F., Talagrand, O., 1993. Meteorological variability and the annual surface pressure cycle on Mars. Journal of Atmospheric Sciences 50, 3625-3640.

Jakosky, B. M., Farmer, C. B., Apr. 1982. The seasonal and global behavior of 
water vapor in the Mars atmosphere - Complete global results of the Viking atmospheric water detector experiment. Journal of Geophysical Research 87, 2999-3019.

James, P. B., Bell, J. F., Clancy, R. T., Lee, S. W., Martin, L. J., Wolff, M. J., 1996. Global imaging of Mars by Hubble space telescope during the 1995 opposition. Journal of Geophysical Research 101, 18883-18890.

James, P. B., Cantor, B. A., Nov. 2001. Martian North Polar Cap Recession: 2000 Mars Orbiter Camera Observations. Icarus 154, 131-144.

Joshi, M. M., Haberle, R. M., Barnes, J. R., Murphy, J. R., Schaeffer, J., Mar. 1997. Low-level jets in the NASA Ames Mars general circulation model. Journal of Geophysical Research 102, 6511-6524.

Kadish, S. J., Head, J. W., Parsons, R. L., Marchant, D. R., Sep. 2008. The Ascraeus Mons fan-shaped deposit: Volcano ice interactions and the climatic implications of cold-based tropical mountain glaciation. Icarus 197, 84-109. Kahn, R., Aug. 1984. The spatial and seasonal distribution of Martian clouds and some meteorological implications. Journal of Geophysical Research 89, 6671-6688.

Kieffer, H. H., Titus, T. N., Nov. 2001. TES Mapping of Mars' North Seasonal Cap. Icarus 154, 162-180.

Kostama, V.-P., Kreslavsky, M. A., Head, J. W., Jun. 2006. Recent highlatitude icy mantle in the northern plains of Mars: Characteristics and ages of emplacement. Geophysical Research Letters 33, 11201-+.

Kowalewski, D. E., Marchant, D. R., Levy, J. S., Head, J. W., 2006. Quantifying low rates of summertime sublimation for buried glacier ice in Beacon Valley, Antarctica. Antarctic Science 18 (03), 421-428.

Kreslavsky, M. A., Head, J. W., Nov. 2000. Kilometer-scale roughness of Mars: Results from MOLA data analysis. Journal of Geophysical Research 105, 
26695-26712.

Kreslavsky, M. A., Head, J. W., Aug. 2002. Mars: Nature and evolution of young latitude-dependent water-ice-rich mantle. Geophysical Research Letters $29,14-1$.

Lambert, F., Delmonte, B., Petit, J., Bigler, M., Kaufmann, P., Hutterli, M., Stocker, T., Ruth, U., Steffensen, J., Maggi, V., 2008. Dust-climate couplings over the past 800,000 years from the EPICA Dome C ice core. Nature 452 (7187), 616-9.

Langevin, Y., Poulet, F., Bibring, J.-P., Schmitt, B., Douté, S., Gondet, B., Mar. 2005. Summer Evolution of the North Polar Cap of Mars as Observed by OMEGA/Mars Express. Science 307, 1581-1584.

Laskar, J., Correia, A. C. M., Gastineau, M., Joutel, F., Levrard, B., Robutel, P., Aug. 2004. Long term evolution and chaotic diffusion of the insolation quantities of Mars. Icarus 170, 343-364.

Laskar, J., Levrard, B., Mustard, J. F., Sep. 2002. Orbital forcing of the martian polar layered deposits. Nature 419, 375-377.

Laskar, J., Robutel, P., Feb. 1993. The chaotic obliquity of the planets. Nature $361,608-612$.

Lefèvre, F., Lebonnois, S., Montmessin, F., Forget, F., Jul. 2004. Threedimensional modeling of ozone on Mars. Journal of Geophysical Research (Planets) 109, E07004.

Levrard, B., Forget, F., Montmessin, F., Laskar, J., Oct. 2004. Recent icerich deposits formed at high latitudes on Mars by sublimation of unstable equatorial ice during low obliquity. Nature 431, 1072-1075.

Levrard, B., Forget, F., Montmessin, F., Laskar, J., Jun. 2007. Recent formation and evolution of northern Martian polar layered deposits as inferred from a Global Climate Model. Journal of Geophysical Research (Planets) 
112, E06012.

Levy, J. S., Head, J. W., Marchant, D. R., Aug. 2007. Lineated valley fill and lobate debris apron stratigraphy in Nilosyrtis Mensae, Mars: Evidence for phases of glacial modification of the dichotomy boundary. Journal of Geophysical Research (Planets) 112, 8004-+.

Lucchitta, B. K., Feb. 1981. Mars and Earth - Comparison of cold-climate features. Icarus 45, 264-303.

Mangold, N., Jan. 2003. Geomorphic analysis of lobate debris aprons on Mars at Mars Orbiter Camera scale: Evidence for ice sublimation initiated by fractures. Journal of Geophysical Research (Planets) 108, 8021.

Marchant, D. R., Head, J. W., Dec. 2007. Antarctic dry valleys: Microclimate zonation, variable geomorphic processes, and implications for assessing climate change on Mars. Icarus 192, 187-222.

Milkovich, S. M., Head, J. W., Jan. 2005. North polar cap of Mars: Polar layered deposit characterization and identification of a fundamental climate signal. Journal of Geophysical Research (Planets) 110, E01005.

Milkovich, S. M., Head, J. W., Marchant, D. R., Apr. 2006. Debris-covered piedmont glaciers along the northwest flank of the Olympus Mons scarp: Evidence for low-latitude ice accumulation during the Late Amazonian of Mars. Icarus 181, 388-407.

Milliken, R. E., Mustard, J. F., Goldsby, D. L., Jun. 2003. Viscous flow features on the surface of Mars: Observations from high-resolution Mars Orbiter Camera (MOC) images. Journal of Geophysical Research (Planets) 108, 5057.

Mischna, M. A., Richardson, M. I., Feb. 2005. A reanalysis of water abundances in the Martian atmosphere at high obliquity. Geophysical Research Letters 32, L03201. 
Mischna, M. A., Richardson, M. I., Wilson, R. J., McCleese, D. J., Jun. 2003. On the orbital forcing of Martian water and $\mathrm{CO}_{2}$ cycles: A general circulation model study with simplified volatile schemes. Journal of Geophysical Research (Planets) 108, 16-1.

Montmessin, F., Forget, F., Rannou, P., Cabane, M., Haberle, R. M., Oct. 2004. Origin and role of water ice clouds in the Martian water cycle as inferred from a general circulation model. Journal of Geophysical Research (Planets) 109, E10004.

Montmessin, F., Fouchet, T., Forget, F., Mar. 2005. Modeling the annual cycle of HDO in the Martian atmosphere. Journal of Geophysical Research (Planets) 110, E03006.

Montmessin, F., Haberle, R. M., Forget, F., Langevin, Y., Clancy, R. T., Bibring, J.-P., Aug. 2007. On the origin of perennial water ice at the south pole of Mars: A precession-controlled mechanism? Journal of Geophysical Research (Planets) 112, E08S17.

Montmessin, F., Rannou, P., Cabane, M., Jun. 2002. New insights into Martian dust distribution and water-ice cloud microphysics. Journal of Geophysical Research (Planets) 107, 4-1.

Mustard, J. F., Cooper, C. D., Rifkin, M. K., Jul. 2001. Evidence for recent climate change on Mars from the identification of youthful near-surface ground ice. Nature 412, 411-414.

Nayvelt, L., Gierasch, P. J., Cook, K. H., Sep. 1997. Modeling and Observations of Martian Stationary Waves. Journal of the Atmospheric Sciences $54(8), 986-1013$.

Newman, C. E., Lewis, S. R., Read, P. L., Mar. 2005. The atmospheric circulation and dust activity in different orbital epochs on Mars. Icarus 174, $135-160$. 
Newman, C. E., Lewis, S. R., Read, P. L., Forget, F., Dec. 2002. Modeling the Martian dust cycle 2. Multiannual radiatively active dust transport simulations. Journal of Geophysical Research (Planets) 107, 7-1.

Paige, D., 1992. The thermal stability of near-surface ground ice on Mars. Nature 356 (6364), 43-45.

Paige, D. A., Bachman, J. E., Keegan, K. D., Dec. 1994. Thermal and albedo mapping of the polar regions of Mars using Viking thermal mapper observations: 1. North polar region. Journal of Geophysical Research 99, 2595925991.

Phillips, R. J., 26 colleagues, May 2008. Mars North Polar Deposits: Stratigraphy, Age, and Geodynamical Response. Science 320, 1182-1185.

Plaut, J. J., Safaeinili, A., Holt, J. W., Phillips, R. J., Head, J. W., Seu, R., Putzig, N. E., Frigeri, A., Jan. 2009. Radar evidence for ice in lobate debris aprons in the mid-northern latitudes of Mars. Geophysical Research Letters 36, L02203.

Pollack, J. B., Colburn, D. S., Flasar, F. M., Kahn, R., Carlston, C. E., Pidek, D. G., Jun. 1979. Properties and effects of dust particles suspended in the Martian atmosphere. Journal of Geophysical Research 84, 2929-2945.

Richardson, M. I., Wilson, R. J., May 2002. Investigation of the nature and stability of the Martian seasonal water cycle with a general circulation model. Journal of Geophysical Research (Planets) 107, 7-1.

Richardson, M. I., Wilson, R. J., Rodin, A. V., Sep. 2002. Water ice clouds in the Martian atmosphere: General circulation model experiments with a simple cloud scheme. Journal of Geophysical Research (Planets) 107, 2-1.

Rodin, A. V., Clancy, R. T., Wilson, R. J., 1999. Dynamical properties of Mars water ice clouds and their interactions with atmospheric dust and radiation. Advances in Space Research 23, 1577-1585. 
Shean, D. E., Head, J. W., Fastook, J. L., Marchant, D. R., Mar. 2007. Recent glaciation at high elevations on Arsia Mons, Mars: Implications for the formation and evolution of large tropical mountain glaciers. Journal of Geophysical Research (Planets) 112, E03004.

Shean, D. E., Head, J. W., Marchant, D. R., May 2005. Origin and evolution of a cold-based tropical mountain glacier on Mars: The Pavonis Mons fanshaped deposit. Journal of Geophysical Research (Planets) 110, E05001.

Smith, M. D., Nov. 2002. The annual cycle of water vapor on Mars as observed by the Thermal Emission Spectrometer. Journal of Geophysical Research (Planets) 107, 25-1.

Smith, M. D., Jan. 2004. Interannual variability in TES atmospheric observations of Mars during 1999-2003. Icarus 167, 148-165.

Spiga, A., Forget, F., Feb. 2009. A new model to simulate the Martian mesoscale and microscale atmospheric circulation: Validation and first results. Journal of Geophysical Research (Planets) 114, E02009.

Squyres, S. W., Jun. 1978. Martian fretted terrain - Flow of erosional debris. Icarus 34, 600-613.

Squyres, S. W., Dec. 1979. The distribution of lobate debris aprons and similar flows on Mars. Journal of Geophysical Research 84, 8087-8096.

Tamppari, L. K., Smith, M. D., Bass, D. S., Hale, A. S., Feb. 2008. Water-ice clouds and dust in the north polar region of Mars using MGS TES data. Planetary and Space Science 56, 227-245.

Titus, T. N., Kieffer, H. H., Christensen, P. R., Feb. 2003. Exposed Water Ice Discovered near the South Pole of Mars. Science 299, 1048-1051.

van Leer, B., Mar. 1977. Towards the ultimate conservative difference scheme. III - Upstream-centered finite-difference schemes for ideal compressible flow. IV - A new approach to numerical convection. Journal of Computational 
Physics 23, 263-299.

Wang, H., Ingersoll, A. P., Oct. 2002. Martian clouds observed by Mars Global Surveyor Mars Orbiter Camera. Journal of Geophysical Research (Planets) $107,8-1$.

Wilson, R. J., 1997. A general circulation model simulation of the Martian polar warming. Geophysical Research Letters 24, 123-126.

Wilson, R. J., Neumann, G. A., Smith, M. D., Jan. 2007. Diurnal variation and radiative influence of Martian water ice clouds. Geophysical Research Letters 34, L02710.

Wolff, M. J., James, P. B., Todd Clancy, R., Lee, S. W., Apr. 1999. Hubble Space Telescope observations of the Martian aphelion cloud belt prior to the Pathfinder mission: Seasonal and interannual variations. Journal of Geophysical Research 104, 9027-9042. 
1282

1283

1284

1285

1286

1287

1288

1289

1 Results of the sensitivity tests. Climate parameters are listed on the left, and results are summarized by giving the annual sublimation rate of the equatorial sources, the meridional wind speed at $5.6 \mathrm{~km}$ over Deuteronilus Mensae, along with the zonal mean water vapor and water ice columns at $45^{\circ} \mathrm{N}$ (in pr. $\mu \mathrm{m}$ ) both averaged over the $\mathrm{L}_{\mathrm{S}}=240-270^{\circ}$ period, and finally the annual accumulation rate in three regions indicated in Fig. 7. 


\section{Climate parameters Source Wind speed Water/Ice column Deposits (mm/yr)}

\begin{tabular}{ccccc|ccccccc}
$\#$ & $\epsilon$ & $\mathrm{e}$ & $\mathrm{L}_{\mathrm{p}}$ & $\tau_{\text {dust }}$ & $(\mathrm{cm} / \mathrm{yr})$ & $(\mathrm{m} / \mathrm{s})$ & at $45^{\circ} \mathrm{N}(\mathrm{pr} . \mu \mathrm{m})$ & 1. & 2. & 4. \\
\hline$x_{\text {ref }}$ & $35^{\circ}$ & 0.1 & $270^{\circ}$ & 2.5 & 37 & 8.8 & 186 & 512 & 11.3 & 13.5 & 12.1 \\
$x_{1}$ & $15^{\circ}$ & 0.1 & $270^{\circ}$ & 2.5 & 92 & 9.8 & 165 & 248 & 6.7 & 10.6 & 5.3 \\
$x_{2}$ & $25.2^{\circ}$ & 0.09 & $251^{\circ}$ & 2.5 & 51 & 10.8 & 212 & 503 & 6.3 & 12.5 & 8.9 \\
$x_{3}$ & $35^{\circ}$ & 0.1 & $270^{\circ}$ & 0.2 & 3.4 & 1.4 & 3.4 & 6.3 & 0. & 0. & 0. \\
$x_{4}$ & $35^{\circ}$ & 0.1 & $270^{\circ}$ & 1.5 & 25 & 6.3 & 118 & 260 & 14.1 & 0. & 11.1 \\
$x_{5}$ & $45^{\circ}$ & 0.1 & $270^{\circ}$ & 2.5 & 26 & 4.4 & 154 & 491 & 0. & 0. & 0. \\
$x_{6}$ & $35^{\circ}$ & 0. & & 2.5 & 28 & 4.5 & 77 & 303 & 0. & 0. & 6.2 \\
$x_{7}$ & $35^{\circ}$ & 0.1 & $90^{\circ}$ & 2.5 & 43 & 3.6 & 32 & 157 & 0. & 0. & 0.
\end{tabular}

Table 1

Results of the sensitivity tests. Climate parameters are listed on the left, and results are summarized by giving the annual sublimation rate of the equatorial sources, the meridional wind speed at $5.6 \mathrm{~km}$ over Deuteronilus Mensae, along with the zonal mean water vapor and water ice columns at $45^{\circ} \mathrm{N}$ (in pr. $\mu \mathrm{m}$ ) both averaged over the $\mathrm{L}_{\mathrm{S}}=240-270^{\circ}$ period, and finally the annual accumulation rate in three regions indicated in Fig. 7. 
1 Regions showing evidence of glaciation. The different sites are described in Head and Marchant (2006).

2 Variations of obliquity and eccentricity over the last $10 \mathrm{Myr}$, calculated by Laskar et al. (2004).

3 Latitudinal evolution of the water vapor column (contours, pr. $\mu \mathrm{m}$ ) and water-ice clouds (shaded regions, same unit) as a function of time (in degrees of solar longitude angle $\mathrm{L}_{\mathrm{S}}$ ), under present-day (panel a) and paleoclimatic conditions. Panels $\mathbf{b}$ and $\mathbf{c}$ represent the predicted water cycle when assuming an equatorial water source and a $35^{\circ}$ obliquity, under low dust $\left(\tau_{\text {dust }}=0.2\right)$ and high dust $\left(\tau_{\text {dust }}=2.5\right)$ conditions, respectively. Water sources are indicated by the acronyms NPC (Northern Polar Cap) and TMG (Tropical Mountain Glaciers). MY24 stands for Martian Year 24 (1999-2000).

4 Changes in atmospheric dynamics (upper row), water vapor content (middle row) and water ice content (lower row) under present-day (left column), clear $35^{\circ}$ obliquity (center column) and dusty $35^{\circ}$ obliquity (right column) conditions. The temperature field is shown in each panel, and simulation parameters are labeled at its top. The color scale is given at the bottom of the figure, in Kelvins. Water vapor and ice contents (middle and lower row) are mixing ratios, in $10^{-6} \mathrm{~kg} \mathrm{~kg}^{-1}$. All the fields are zonally and monthly averaged over the $\mathrm{L}_{\mathrm{S}}=240-270^{\circ}$ period. Y-axis is in kilometers above the reference areoid. Water sources are indicated by the acronyms NPC (Northern Polar Cap) and TMG (Tropical Mountain Glaciers). MY24 stands for Martian Year 24 (1999-2000).

5 Polar stereographic map of the Northern Hemisphere. Zonal winds at the $5.6-\mathrm{km}$ level are depicted by shaded colors $\left(\mathrm{m} \mathrm{s}^{-1}\right)$, and water-ice column by contours (pr. $\left.\mu \mathrm{m}\right)$. The fields are averaged over the $\mathrm{L}_{\mathrm{S}}=240-270^{\circ}$ period. Deviations from zonal symmetry are apparent in the jetstream structure, over the Tharsis, Arabia Terra and Elysium ridges. Centers of enhanced cloud formation are indicated by arrows.

6 Average cloud ice content (shaded regions, pr. $\mu \mathrm{m}$ ) and horizontal wind field at the $5.6-\mathrm{km}$ level $\left(\mathrm{m} \mathrm{s}^{-1}\right)$. White lines indicate water vapor column (pr. $\mu \mathrm{m})$. 
7 a. Net ice accumulation $\left(\mathrm{mm} \mathrm{yr}^{-1}\right)$ predicted in simulation $x_{r e f}=\left(35^{\circ}, 0.1,270^{\circ}, 2.5, \mathrm{TMG}\right)$, superposed on the map by Squyres (1979), which shows the specific location of several different types of ice-related features. LDA and LVF stand for Lobate Debris Aprons and Lineated Valley Fill. See also Fig. 1, which shows the areas of widespread glaciation documented in Head and Marchant (2006). Indicated regions: 1. Tempe Terra, 2. Deuteronilus Mensae, 3. Nilosyrtis Mensae, 4. Phlegra Montes. b. Water ice accumulation during the $\mathrm{L}_{\mathrm{S}}=180-360^{\circ}$ period $(\mathrm{mm})$. c. Water ice sublimation during the $\mathrm{L}_{\mathrm{S}}=0-180^{\circ}$ period $(\mathrm{mm})$.

8 Upper panel: Evolution of surface ice deposits in glacial regions (see the legend of Fig. 7). Lower panel: Maximum, minimum (shaded region) and mean (middle line) daily surface temperatures in Deuteronilus Mensae $\left({ }^{\circ} \mathrm{C}\right)$.

9 Net gain of surface ice over a year $\left(\mathrm{mm} \mathrm{yr}^{-1}\right)$ for each sensitivity experiment. Details can be found in Table 1.

10 Net ice accumulation $\left(\mathrm{mm} \mathrm{yr}^{-1}\right)$ predicted in simulation $x_{7}=\left(35^{\circ}, 0.1,90^{\circ}, 2.5, \mathrm{TMG}\right)$, superposed on the map by Squyres (1979). LDA and LVF stand for Lobate Debris Aprons and Lineated Valley Fill. Indicated regions: 1. Argyre Planitia, 2. Western Hellas, 3. Terra Sirenum (left) and Terra Cimmeria (right).

11 Results of the 1-D model showing the impact of ice thermal inertia on surface temperatures at $45^{\circ} \mathrm{N}$ and under reference conditions (see Table 1). Contours and dark shades indicate annual maximum and mean temperatures, respectively. Ice thermal inertia and albedo are set to $1000 \mathrm{~J} \mathrm{~s}^{-1 / 2} \mathrm{~m}^{-2} \mathrm{~K}^{-1}$ and 0.4 , respectively.

12 Sensitivity of net ice accumulation rates $\left(\mathrm{mm} \mathrm{yr}^{-1}\right)$ to different surface properties: a. Thermal inertia of the deposited ice is set to $\mathrm{TI}=1000 \mathrm{~J} \mathrm{~s}^{-1 / 2} \mathrm{~m}^{-2} \mathrm{~K}^{-1}$. b. Thermal inertia of the equatorial reservoirs and deposited ice layers is set to $\mathrm{TI}=1000 \mathrm{~J} \mathrm{~s}^{-1 / 2} \mathrm{~m}^{-2} \mathrm{~K}^{-1}$. c. Same as b., but albedo of the equatorial reservoirs is set to 0.2 instead of 0.4 , assuming rock glaciers being darkened by the debris cover. Climate parameters are those of the reference simulation (see $x_{r e f}$ in Table 1). All the results are shown for the tenth year of simulation. 
13 Major components of the climate system related to the northern mid-latitude glaciation. Orbital parameters represent the only external forcing, whereas dust content of the atmosphere and changing surface properties are sources of internal oscillations. These three factors control lower atmosphere temperature, the meridional temperature gradient, and surface temperature. Lower atmosphere temperature acts on water vapor holding capacity, and the meridional temperature gradient controls the cloudiness of the northern mid-latitudes, that is dependent on the eddy heat flux induced by transient and stationary waves. The meridional temperature gradient also changes the Hadley cell and dust lifting activity, the latter providing condensation nuclei to the water cycle. This all leads to precipitation in the storm-track region and accumulation of ice, whose preservation is finally dictated by surface temperature. Dotted arrows with question marks indicate physical processes that are unresolved by the LMD/GCM, and also feed back on the original atmospheric response to external forcing. 


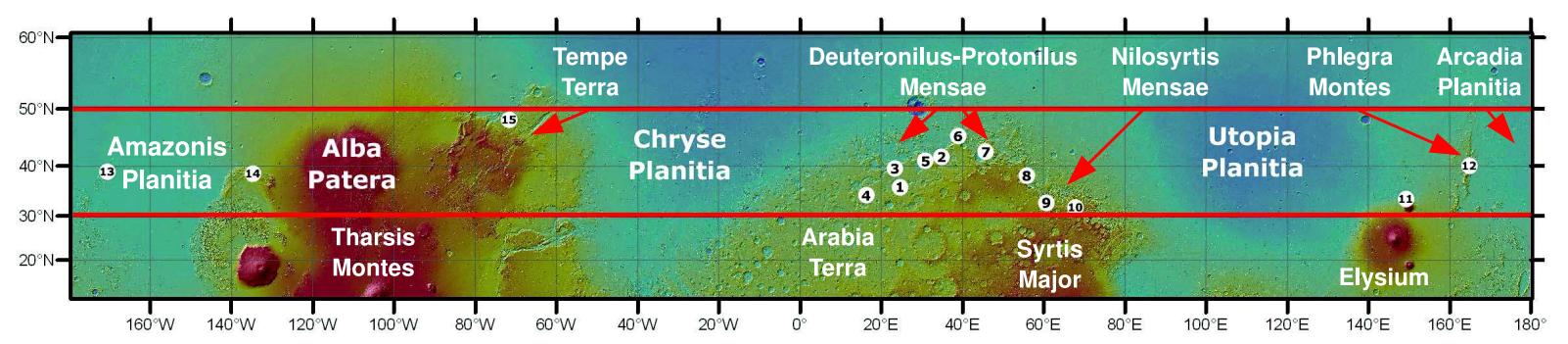

Fig. 1. Regions showing evidence of glaciation. The different sites are described in Head and Marchant (2006). 

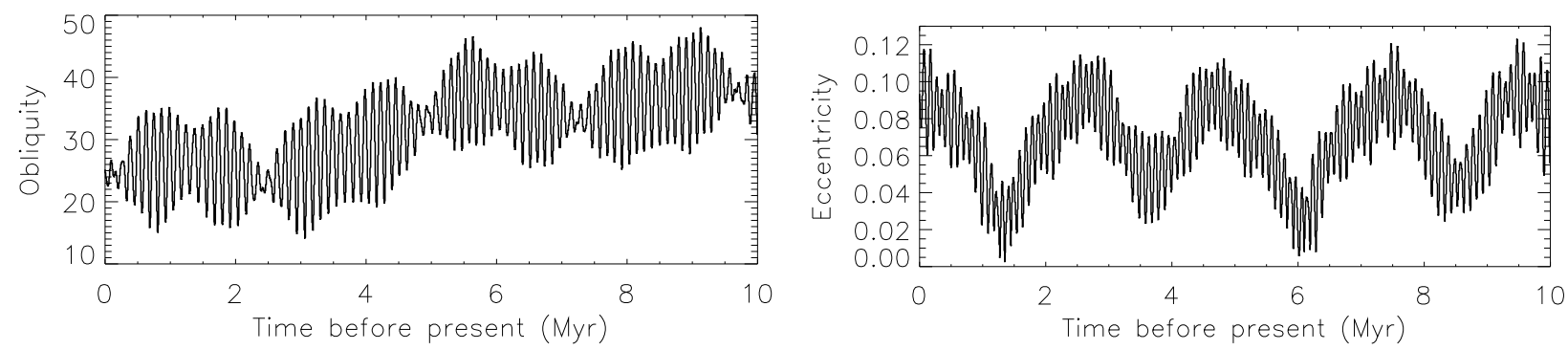

Fig. 2. Variations of obliquity and eccentricity over the last $10 \mathrm{Myr}$, calculated by Laskar et al. (2004). 


\section{a. Present-day}

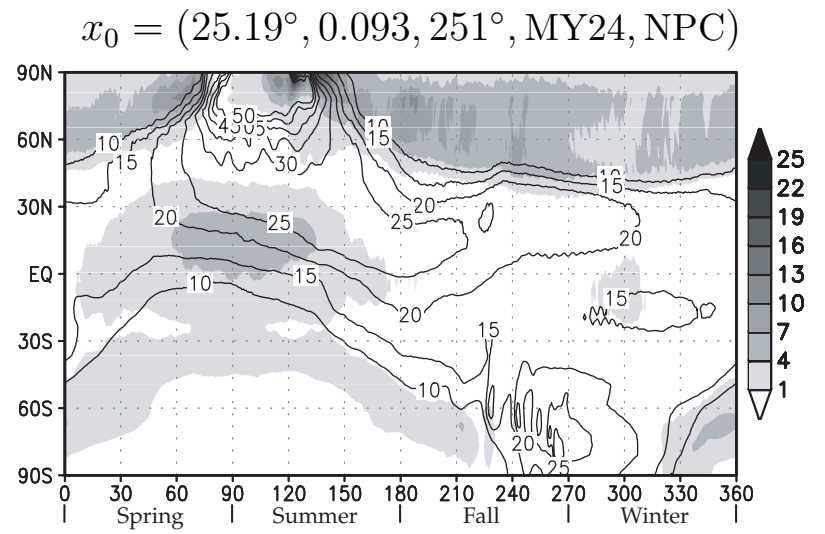

b. $35^{\circ}$ obliquity - Clear

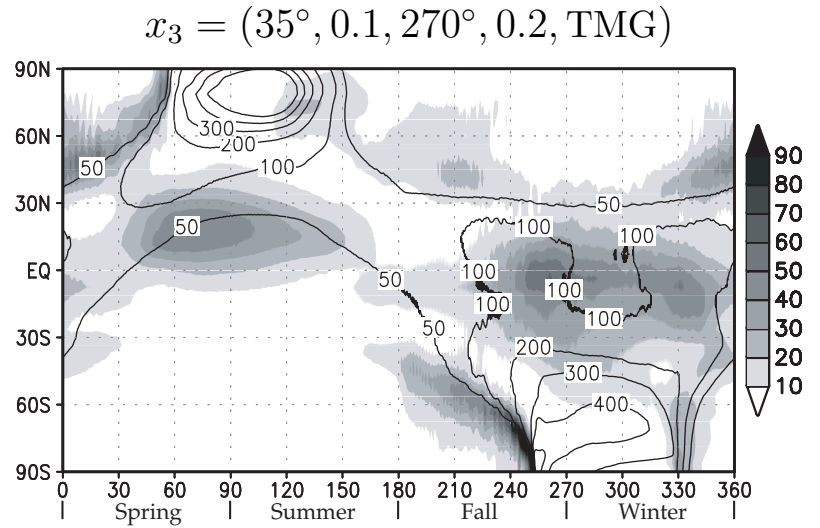

c. $35^{\circ}$ obliquity - Dusty

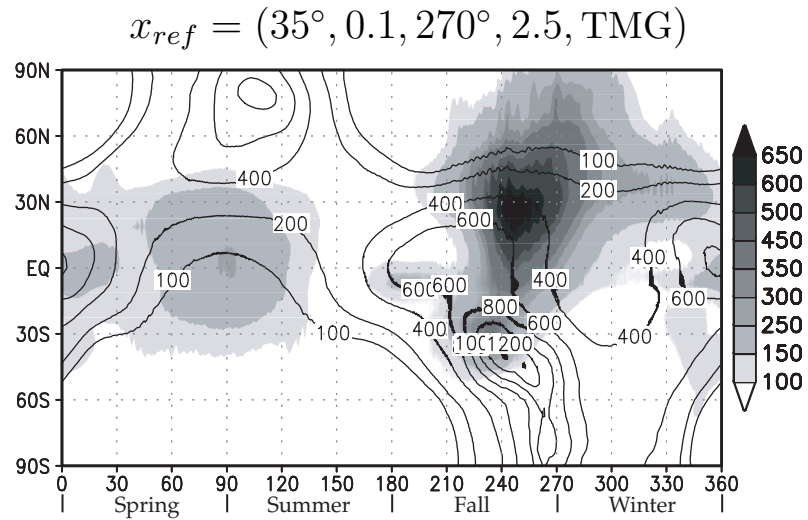

Fig. 3. Latitudinal evolution of the water vapor column (contours, pr. $\mu \mathrm{m}$ ) and water-ice clouds (shaded regions, same unit) as a function of time (in degrees of solar longitude angle $\mathrm{L}_{\mathrm{S}}$ ), under present-day (panel a) and paleoclimatic conditions. Panels $\mathbf{b}$ and $\mathbf{c}$ represent the predicted water cycle when assuming an equatorial water source and a $35^{\circ}$ obliquity, under low dust $\left(\tau_{\text {dust }}=0.2\right)$ and high dust $\left(\tau_{\text {dust }}=2.5\right)$ conditions, respectively. Water sources are indicated by the acronyms NPC (Northern Polar Cap) and TMG (Tropical Mountain Glaciers). MY24 stands for Martian Year 24 (1999-2000). 


\section{a. Present-day}

$x_{0}=\left(25.19^{\circ}, 0.093,251^{\circ}, \mathrm{MY} 24, \mathrm{NPC}\right)$ d. $35^{\circ}$ obliquity - Clear

$x_{3}=\left(35^{\circ}, 0.1,270^{\circ}, 0.2, \mathrm{TMG}\right)$

\section{g. $35^{\circ}$ obliquity - Dusty}

$x_{\text {ref }}=\left(35^{\circ}, 0.1,270^{\circ}, 2.5, \mathrm{TMG}\right)$

Temperature (shaded colors, $\mathrm{K}$ ) and zonal wind (contours, $\mathrm{m} \mathrm{s}^{-1}$ ).

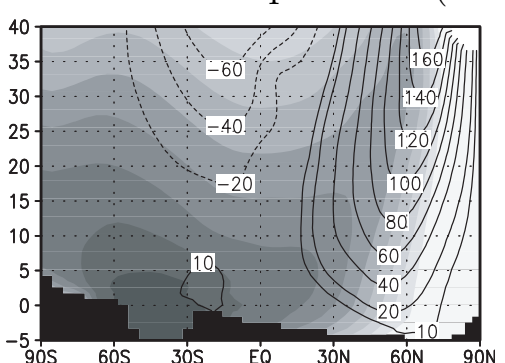

b. Present-day

$x_{0}=\left(25.19^{\circ}, 0.093,251^{\circ}, \mathrm{MY} 24, \mathrm{NPC}\right)$

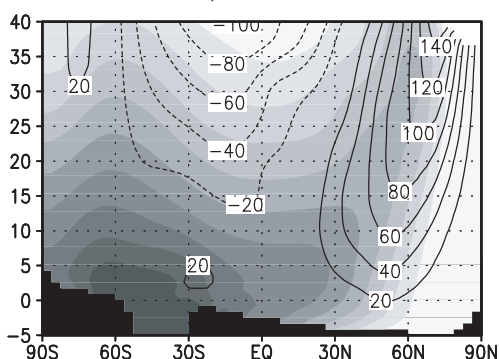

e. $35^{\circ}$ obliquity - Clear

$x_{3}=\left(35^{\circ}, 0.1,270^{\circ}, 0.2, \mathrm{TMG}\right)$

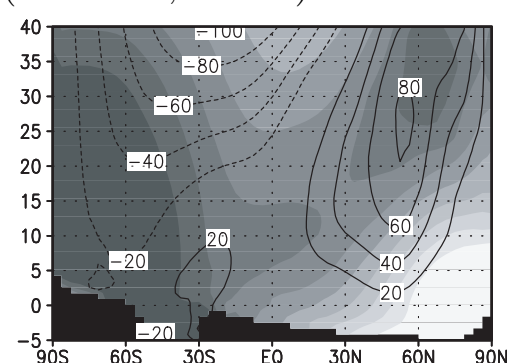

h. $35^{\circ}$ obliquity - Dusty

Temperature (shaded colors, K) and water vapor mixing ratio (contours, $10^{-6} \mathrm{~kg} \mathrm{~kg}^{-1}$ ).

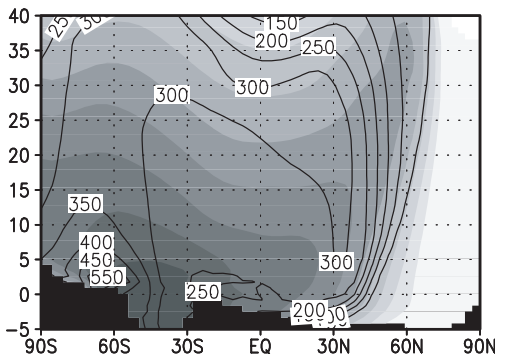

c. Present-day

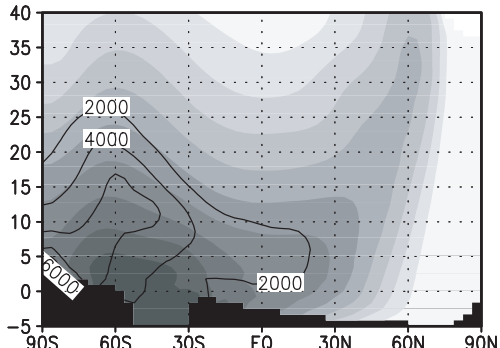

f. $35^{\circ}$ obliquity - Clear

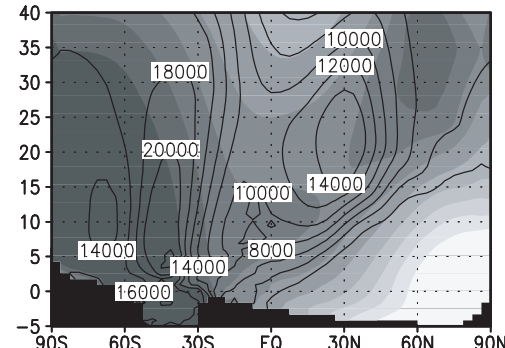

i. $35^{\circ}$ obliquity - Dusty

$x_{\text {ref }}=\left(35^{\circ}, 0.1,270^{\circ}, 2.5, \mathrm{TMG}\right)$

$x_{0}=\left(25.19^{\circ}, 0.093,251^{\circ}, \mathrm{MY} 24, \mathrm{NPC}\right)$

$$
x_{3}=\left(35^{\circ}, 0.1,270^{\circ}, 0.2, \mathrm{TMG}\right)
$$

Temperature (shaded colors, K) and water ice mixing ratio (contours, $10^{-6} \mathrm{~kg} \mathrm{~kg}^{-1}$ ).
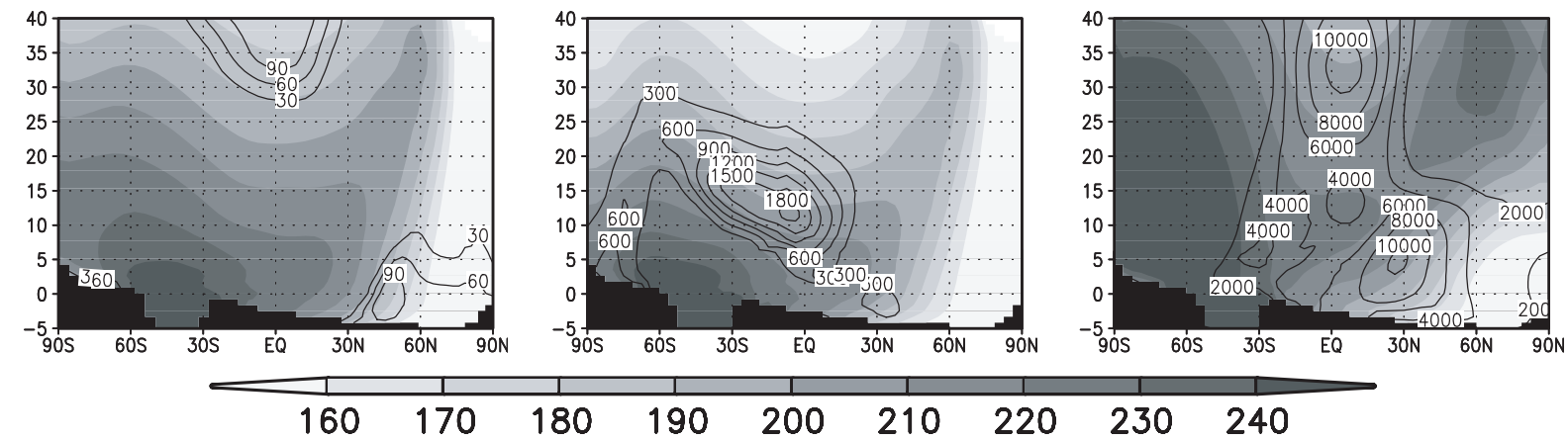

Fig. 4. Changes in atmospheric dynamics (upper row), water vapor content (middle row) and water ice content (lower row) under present-day (left column), clear $35^{\circ}$ obliquity (center column) and dusty $35^{\circ}$ obliquity (right column) conditions. The temperature field is shown in each panel, and simulation parameters are labeled at its top. The color scale is given at the bottom of the figure, in Kelvins. Water vapor and ice contents (middle and lower row) are mixing ratios, in $10^{-6} \mathrm{~kg} \mathrm{~kg}^{-1}$. All the fields are zonally and monthly averaged over the $\mathrm{L}_{\mathrm{S}}=240-270^{\circ}$ period. $\mathrm{Y}$-axis is in kilometers above the reference areoid. Water sources are indicated by the acronyms NPC (Northern Polar Cap) and TMG (Tropical Mountain Glaciers). MY24 stands for Martian Year 24 (1999-2000). 
a. Present-day

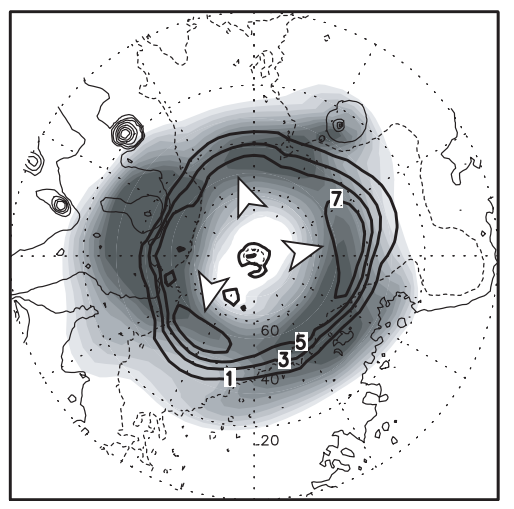

b. $35^{\circ}$ obliquity - Clear

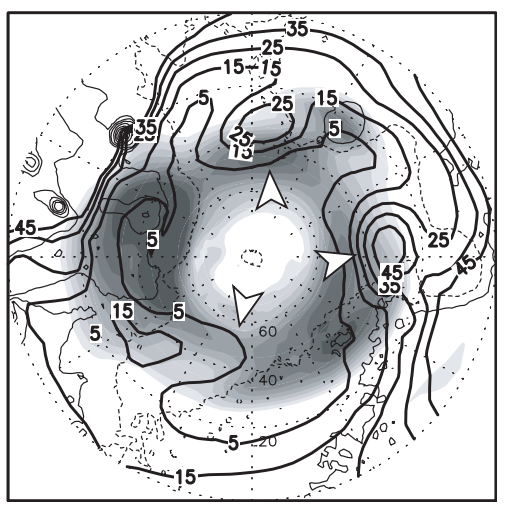

c. $35^{\circ}$ obliquity - Dusty
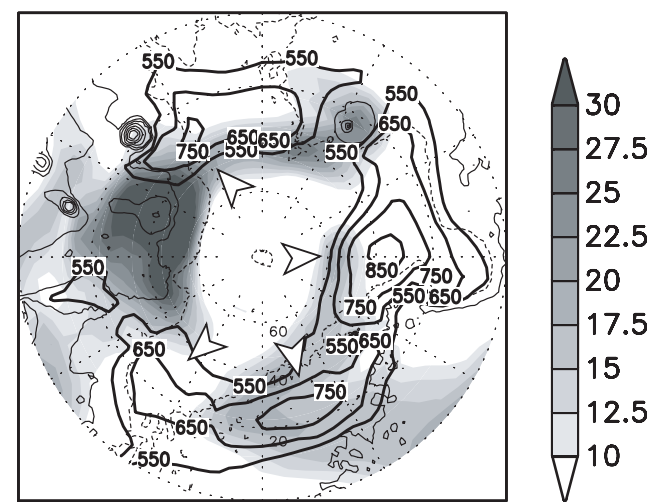

Fig. 5. Polar stereographic map of the Northern Hemisphere. Zonal winds at the $5.6-\mathrm{km}$ level are depicted by shaded colors $\left(\mathrm{m} \mathrm{s}^{-1}\right)$, and water-ice column by contours (pr. $\mu \mathrm{m}$ ). The fields are averaged over the $\mathrm{L}_{\mathrm{S}}=240-270^{\circ}$ period. Deviations from zonal symmetry are apparent in the jetstream structure, over the Tharsis, Arabia Terra and Elysium ridges. Centers of enhanced cloud formation are indicated by arrows. 
Reference simulation ( $35^{\circ}$ obliquity and dusty conditions) $-\mathrm{L}_{\mathrm{S}}=240-270^{\circ}$

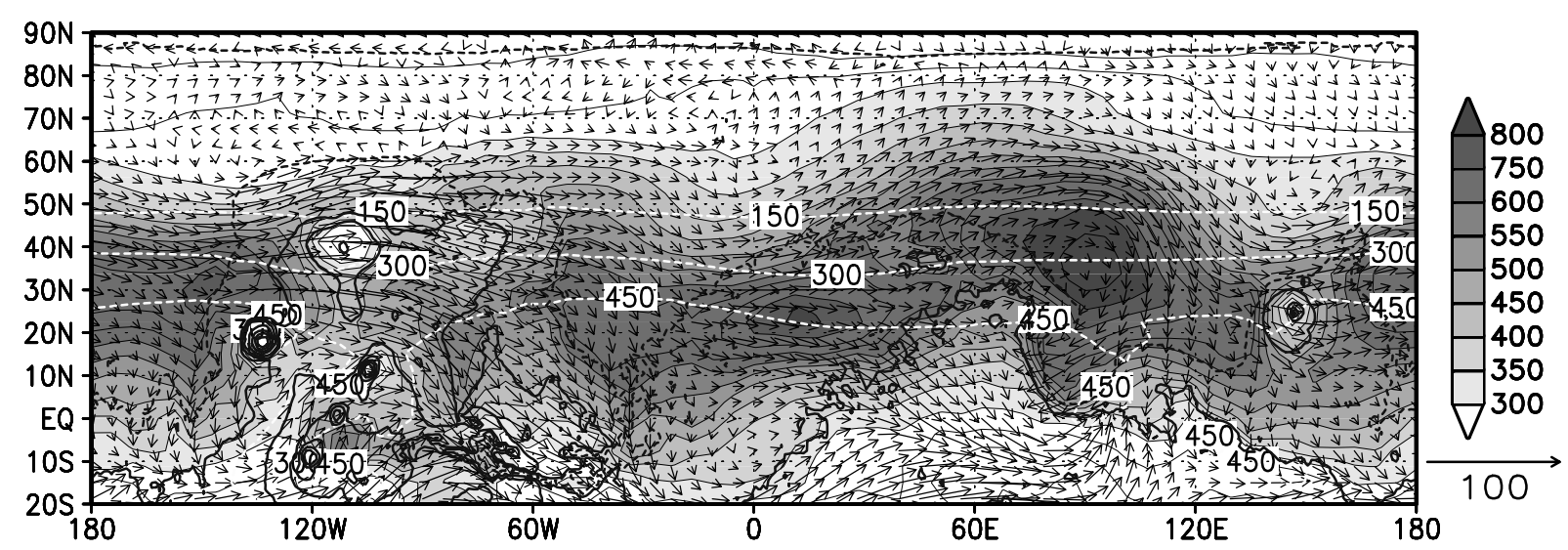

Fig. 6. Average cloud ice content (shaded regions, pr. $\mu \mathrm{m}$ ) and horizontal wind field at the $5.6-\mathrm{km}$ level $\left(\mathrm{m} \mathrm{s}^{-1}\right)$. White lines indicate water vapor column (pr. $\left.\mu \mathrm{m}\right)$. 
a. Surface water-ice budget $(\mathrm{mm} / \mathrm{yr})$

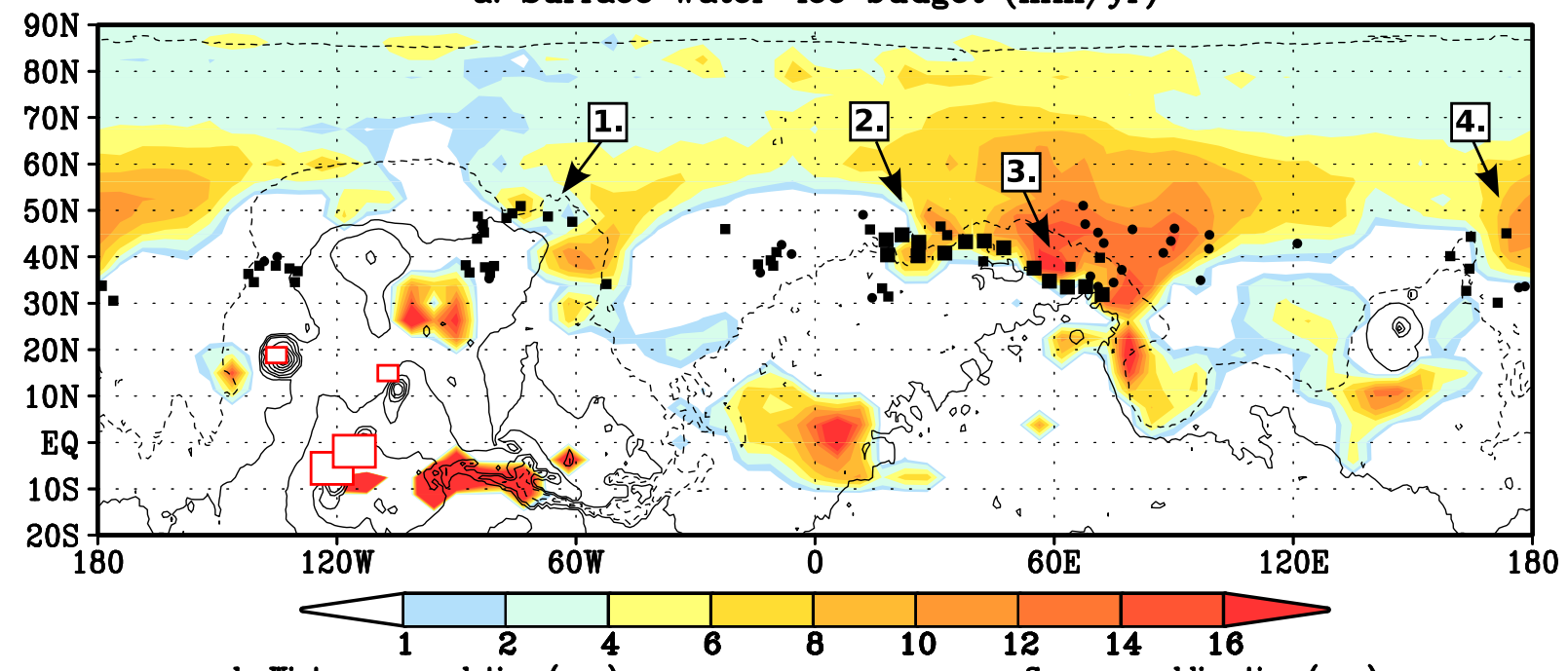

b. Winter accumulation (mm)

c. Summer sublimation (mm)

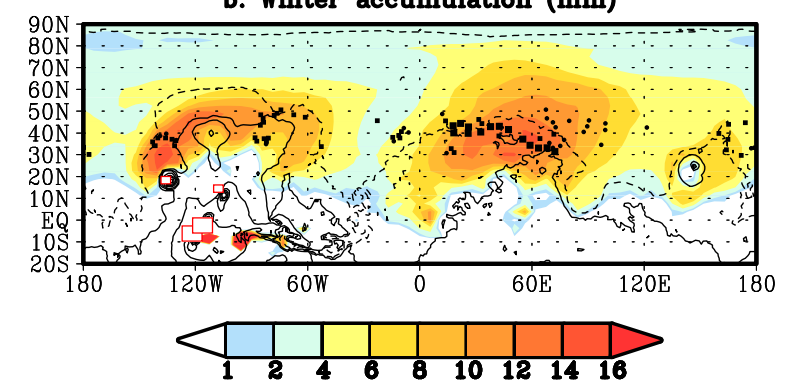

$\square$ GCM Water Ice Reservoirs (WIR)

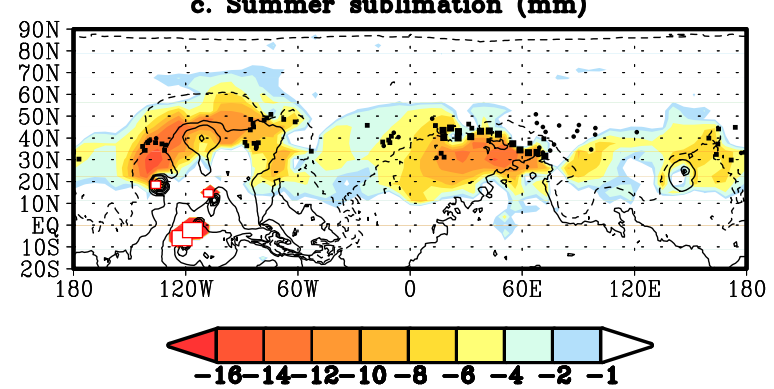

Map by Squyres (1979):

- Concentric crater fill
LDA \& LVF

Fig. 7. a. Net ice accumulation $\left(\mathrm{mm} \mathrm{yr}^{-1}\right)$ predicted in simulation $x_{\text {ref }}=\left(35^{\circ}, 0.1,270^{\circ}, 2.5, \mathrm{TMG}\right)$, superposed on the map by Squyres (1979), which shows the specific location of several different types of ice-related features. LDA and LVF stand for Lobate Debris Aprons and Lineated Valley Fill. See also Fig. 1, which shows the areas of widespread glaciation documented in Head and Marchant (2006). Indicated regions: 1. Tempe Terra, 2. Deuteronilus Mensae, 3. Nilosyrtis Mensae, 4. Phlegra Montes. b. Water ice accumulation during the $\mathrm{L}_{\mathrm{S}}=180-360^{\circ}$ period $(\mathrm{mm})$. c. Water ice sublimation during the $\mathrm{L}_{\mathrm{S}}=0-180^{\circ}$ period $(\mathrm{mm})$. 


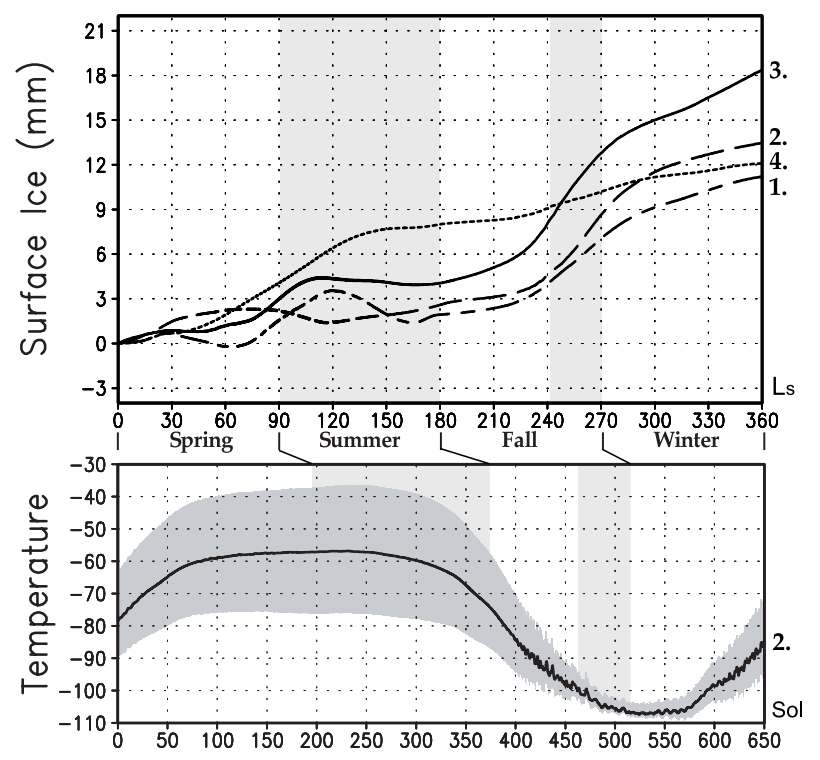

Fig. 8. Upper panel: Evolution of surface ice deposits in glacial regions (see the legend of Fig. 7). Lower panel: Maximum, minimum (shaded region) and mean (middle line) daily surface temperatures in Deuteronilus Mensae $\left({ }^{\circ} \mathrm{C}\right)$. 
a. $x_{r e f}=\left(\epsilon=35^{\circ}, e=0.1, L_{p}=270^{\circ}, \tau_{\text {dust }}=2.5\right)$

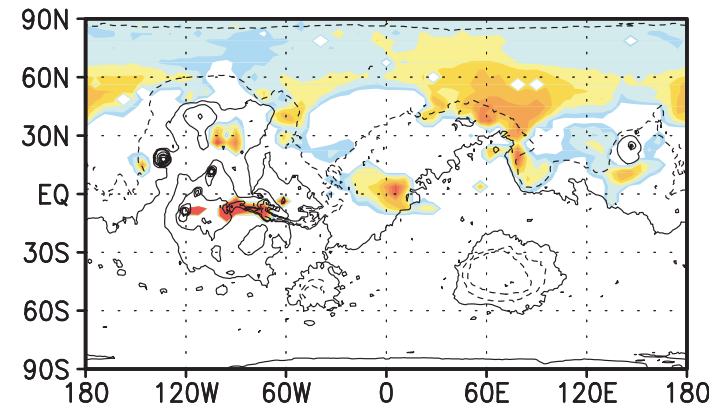

c. $x_{2}=\left(\epsilon=25.19^{\circ}, e=0.093, L_{p}=251^{\circ}, \tau_{\text {dust }}=2.5\right)$

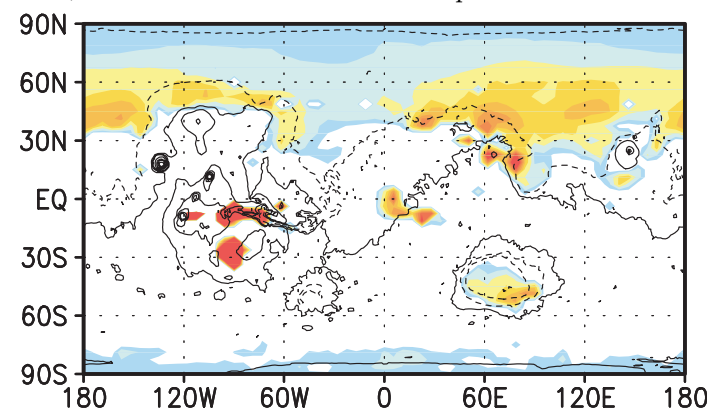

e. $x_{4}=\left(\epsilon=35^{\circ}, e=0.1, L_{p}=270^{\circ}, \tau_{\text {dust }}=1.5\right)$

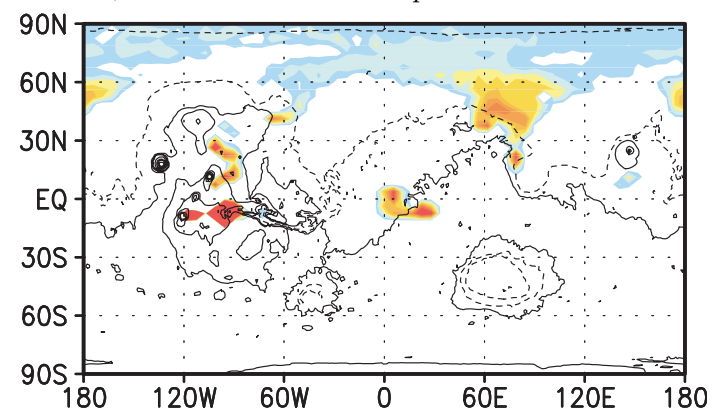

g. $x_{6}=\left(\epsilon=35^{\circ}, e=0, \tau_{\text {dust }}=2.5\right)$

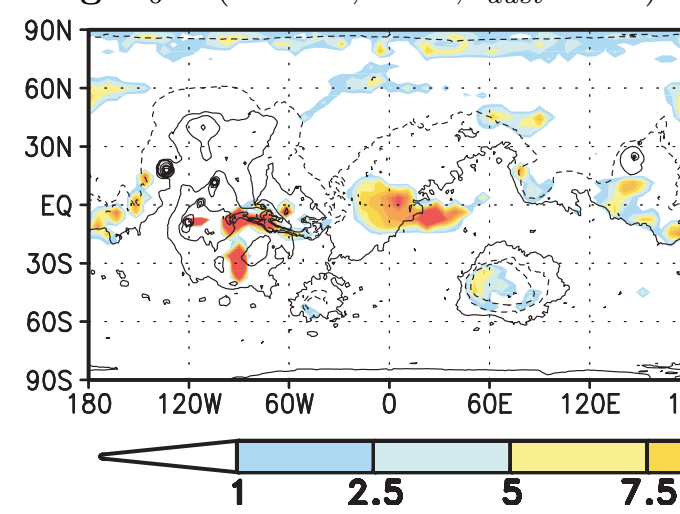

b. $x_{1}=\left(\epsilon=15^{\circ}, e=0.1, L_{p}=270^{\circ}, \tau_{d u s t}=2.5\right)$

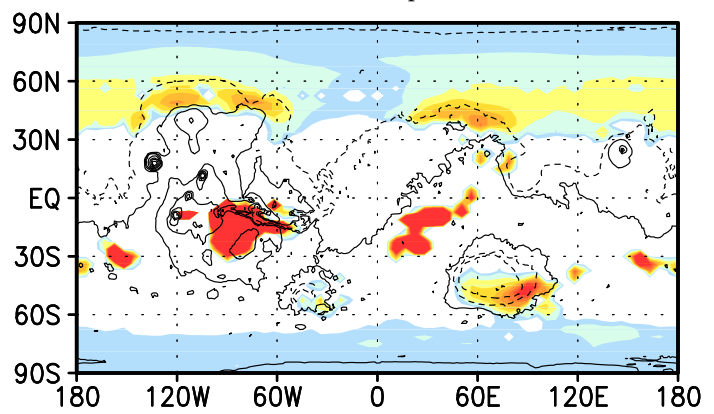

d. $x_{3}=\left(\epsilon=35^{\circ}, e=0.1, L_{p}=270^{\circ}, \tau_{d u s t}=0.2\right)$

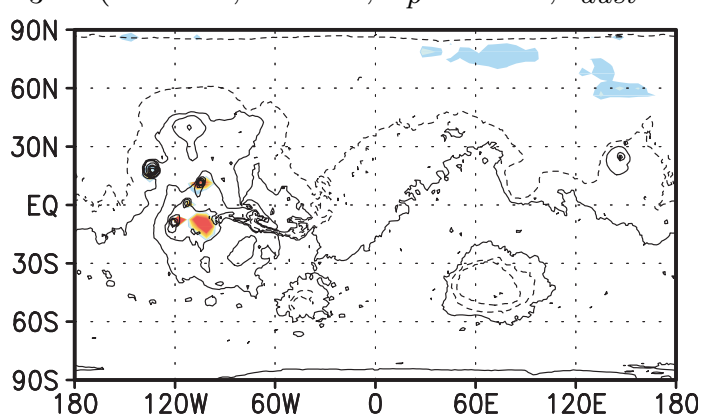

f. $x_{5}=\left(\epsilon=45^{\circ}, e=0.1, L_{p}=270^{\circ}, \tau_{d u s t}=2.5\right)$

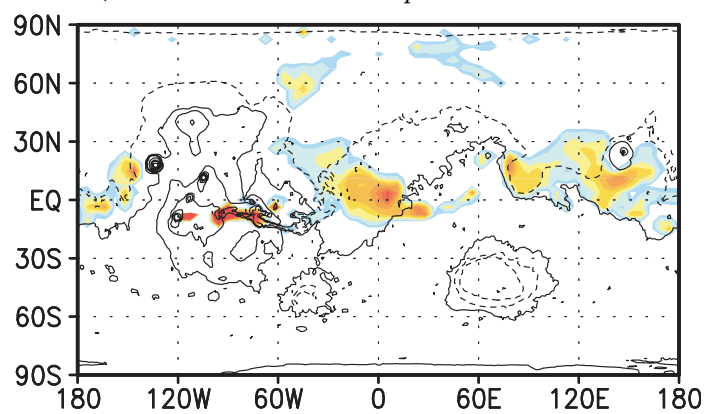

h. $x_{7}=\left(\epsilon=35^{\circ}, e=0.1, L_{p}=90^{\circ}, \tau_{\text {dust }}=2.5\right)$

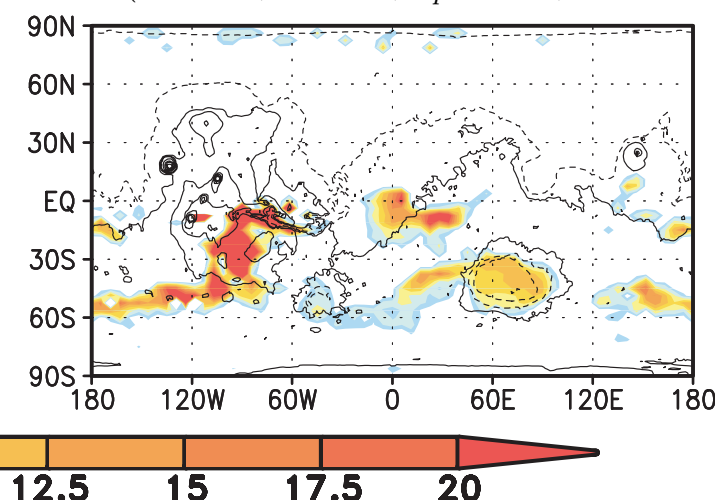

Fig. 9. Net gain of surface ice over a year $\left(\mathrm{mm} \mathrm{yr}^{-1}\right)$ for each sensitivity experiment.

Details can be found in Table 1 . 
Surface water-ice budget $(\mathrm{mm} / \mathrm{yr})$ in southern mid-latitudes (simulation $\mathrm{x} \_7$ ).

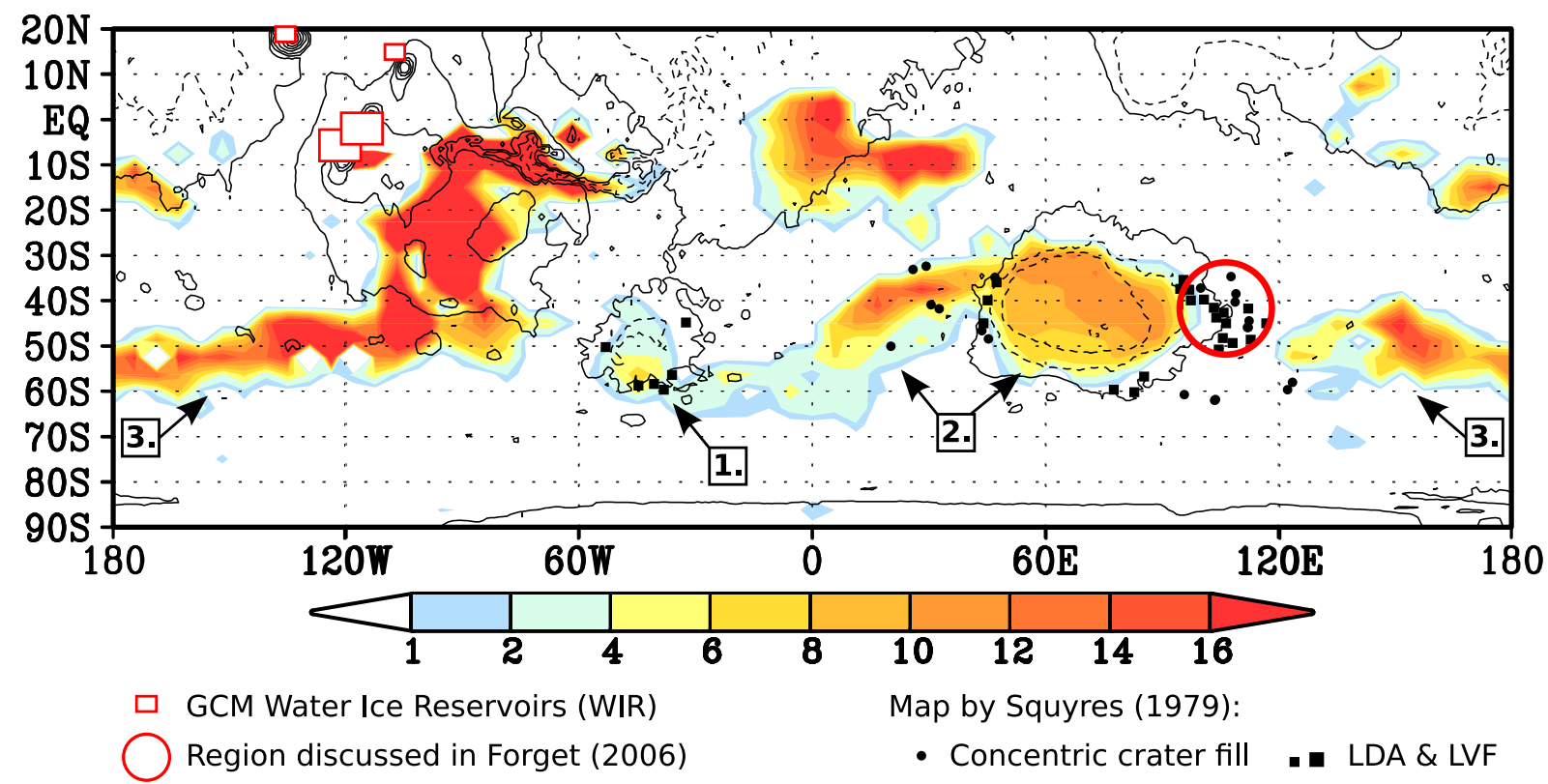

Fig. 10. Net ice accumulation $\left(\mathrm{mm} \quad \mathrm{yr}^{-1}\right)$ predicted in simulation $x_{7}=\left(35^{\circ}, 0.1,90^{\circ}, 2.5, \mathrm{TMG}\right)$, superposed on the map by Squyres (1979). LDA and LVF stand for Lobate Debris Aprons and Lineated Valley Fill. Indicated regions: 1. Argyre Planitia, 2. Western Hellas, 3. Terra Sirenum (left) and Terra Cimmeria (right). 


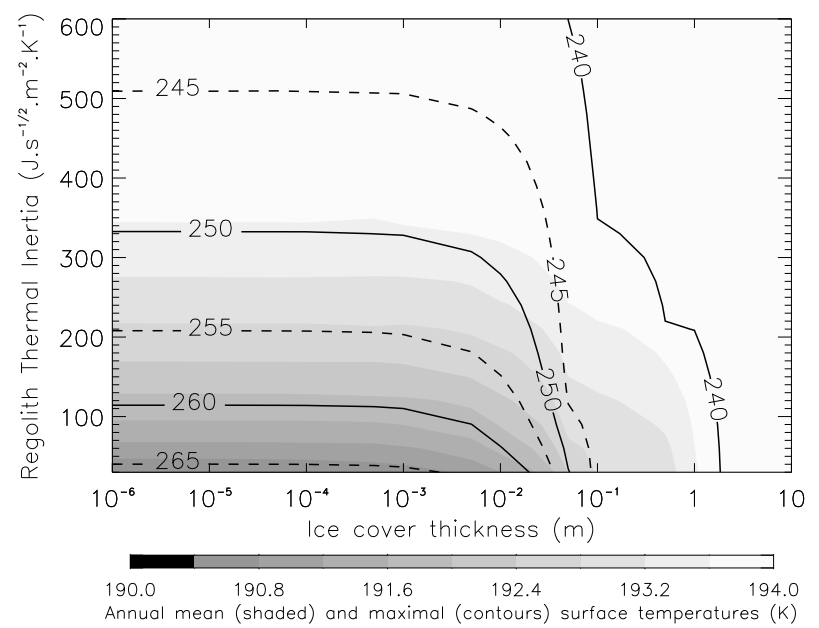

Fig. 11. Results of the 1-D model showing the impact of ice thermal inertia on surface temperatures at $45^{\circ} \mathrm{N}$ and under reference conditions (see Table 1). Contours and dark shades indicate annual maximum and mean temperatures, respectively. Ice thermal inertia and albedo are set to $1000 \mathrm{~J} \mathrm{~s}^{-1 / 2} \mathrm{~m}^{-2} \mathrm{~K}^{-1}$ and 0.4 , respectively. 
a. TI feedback is active on deposited ice only

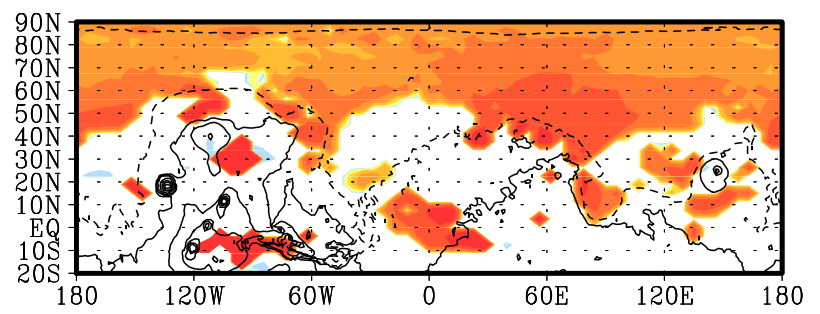

b. TI feedback is active also on the sources

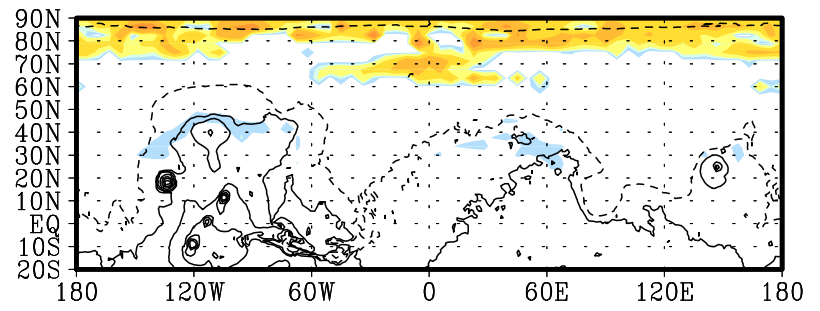

c. Same as b., but source albedo is set to 0.2

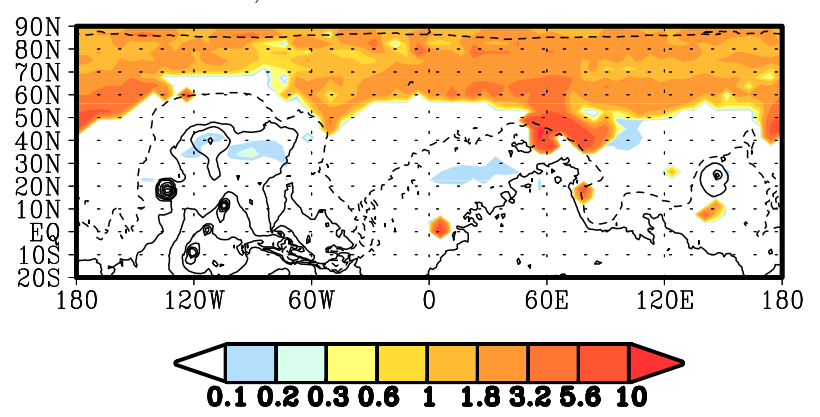

Fig. 12. Sensitivity of net ice accumulation rates $\left(\mathrm{mm} \mathrm{yr}^{-1}\right)$ to different surface properties: a. Thermal inertia of the deposited ice is set to $\mathrm{TI}=1000 \mathrm{~J} \mathrm{~s}^{-1 / 2} \mathrm{~m}^{-2} \mathrm{~K}^{-1}$. b. Thermal inertia of the equatorial reservoirs and deposited ice layers is set to $\mathrm{TI}=1000 \mathrm{~J} \mathrm{~s}^{-1 / 2} \mathrm{~m}^{-2} \mathrm{~K}^{-1}$. c. Same as b., but albedo of the equatorial reservoirs is set to 0.2 instead of 0.4 , assuming rock glaciers being darkened by the debris cover. Climate parameters are those of the reference simulation (see $x_{r e f}$ in Table 1). All the results are shown for the tenth year of simulation. 


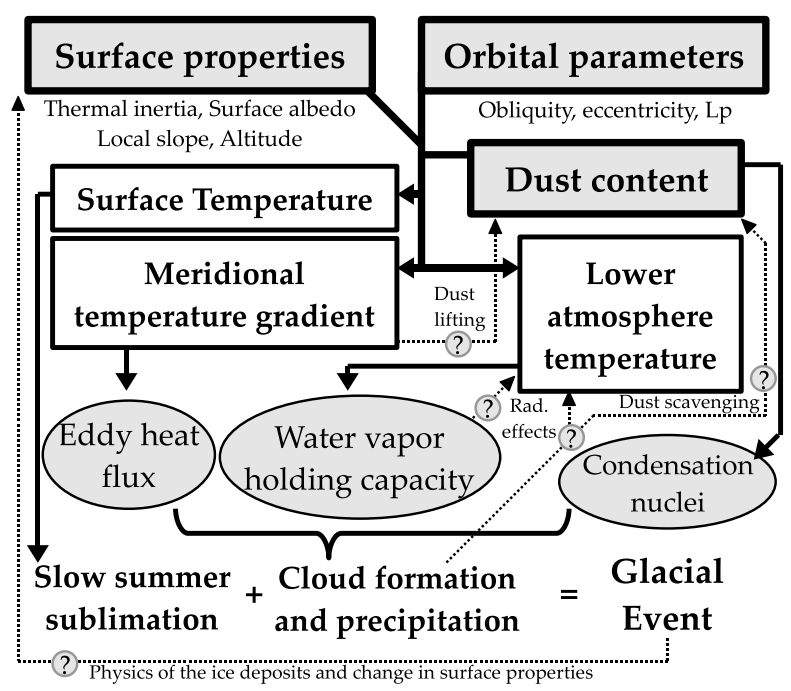

Fig. 13. Major components of the climate system related to the northern mid-latitude glaciation. Orbital parameters represent the only external forcing, whereas dust content of the atmosphere and changing surface properties are sources of internal oscillations. These three factors control lower atmosphere temperature, the meridional temperature gradient, and surface temperature. Lower atmosphere temperature acts on water vapor holding capacity, and the meridional temperature gradient controls the cloudiness of the northern mid-latitudes, that is dependent on the eddy heat flux induced by transient and stationary waves. The meridional temperature gradient also changes the Hadley cell and dust lifting activity, the latter providing condensation nuclei to the water cycle. This all leads to precipitation in the storm-track region and accumulation of ice, whose preservation is finally dictated by surface temperature. Dotted arrows with question marks indicate physical processes that are unresolved by the LMD/GCM, and also feed back on the original atmospheric response to external forcing. 